Vega-Pozuelo, R., Torres-Márquez, M. y Naranjo-Ramírez, J. (2017): “Recursos cartográficos y geohistóricos para el inventario de humedales temporales y desecados mediterráneos”, GeoFocus (Artículos), no 19, p. 151-179. ISSN: 1578-5157 http://dx.doi.org/10.21138/GF.540

\title{
RECURSOS CARTOGRÁFICOS Y GEOHISTÓRICOS PARA EL INVENTARIO DE HUMEDALES TEMPORALES Y DESECADOS MEDITERRÁNEOS
}

\author{
RAFAEL VEGA-POZUELO ${ }^{1}$, MARTÍN TORRES-MÁRQUEZ ${ }^{2}$ Y JOSÉ NARANJO- \\ RAMÍREZ ${ }^{3}$ \\ Departamento de Geografía y Ciencias del Territorio. Universidad de Córdoba Facultad de \\ Filosofía y Letras - Plaza Cardenal Salazar, 314071 Córdoba (España) \\ a72vepor@uco.es ${ }^{1}$, gtltomam@uco.es ${ }^{2}$, chlnaraj@uco.es
}

RESUMEN

El presente artículo recopila y examina, desde una vertiente metodológica y geográfica, las fuentes o recursos cartográficos que se han analizado y utilizado para la realización del inventario de humedales temporales en el Medio Guadalquivir, y en el seno de nuestro proyecto de investigación.

Estudiaremos fundamentalmente las fuentes cartográficas disponibles para el área citada, aunque en gran medida puedan ser extrapolables a la mayor parte de España.

Se lleva a cabo una exposición de las líneas de trabajo y de los autores más representativos para el inventario de humedales temporales o desecados, mediante la investigación de la historia de los Archivos, de las Bibliotecas, de los Museos y de los Centros de Documentación convencionales y digitales actuales. En un segundo momento se aborda una propuesta metodológica para la investigación de esta faceta particular, acompañada por un nutrido apéndice en el que se recopilan las fuentes más significativas que venimos utilizando en nuestra investigación.

Palabras clave: humedales, inventario, cuenca del Guadalquivir, paisaje, cartografía, SIG.

\section{CARTOGRAPHIC AND GEOHISTORIC RESOURCES FOR THE INVENTORY OF TEMPORARY WETLANDS AND MEDITERRANEAN DESECTIONS}

\section{ABSTRACT}

This paper compiles and examines, from a methodological and geographical perspective, the sources or cartographic resources that have been analyzed and used for the realization of the inventory of temporary wetlands in the Middle Guadalquivir, and within our research project.

We will study fundamentally the cartographic sources available for the mentioned area, 
Vega-Pozuelo, R., Torres-Márquez, M. y Naranjo-Ramírez, J. (2017): “Recursos cartográficos y geohistóricos para el inventario de humedales temporales y desecados mediterráneos", GeoFocus (Artículos), no 19, p. 151-179. ISSN: 1578-5157 http://dx.doi.org/10.21138/GF.540

although to a large extent they can be extrapolated to the greater part of Spain.

An exposition of the lines of work and of the most representative authors for the inventory of temporary or dried wetlands is carried out, through the investigation of the History of Archives, of Libraries, of Museums and of Conventional Documentation Centers And digital technologies. In a second moment, a methodological proposal for the investigation of this particular facet is approached, accompanied by several appendices in which are collected the most significant sources that we have been using in our investigation.

Keywords: wetlands, inventory, Guadalquivir, landscape, mapping, GIS.

\section{1.- Introducción}

Las zonas encharcables o humedales temporales mediterráneos son espacios de componente natural predominante y de gran valor intrínseco. Son, por lo tanto, unidades funcionales de las complejas redes ecológicas y parte relevante de la configuración de los paisajes, en los que aún sobreviven notables valores ambientales (Cirujano, 1988). A los referidos humedales han de sumarse, pues participan de sus caracteres ecológicos, el significado ambiental y cultural de las salinas continentales o de interior.

Tales enclaves, a pesar de sus reducidas dimensiones, mantienen la diversidad biológica y, a menudo, son el hábitat temporal o permanente de especies en peligro de extinción. En este contexto, sin embargo, nunca hay que obviar la perspectiva cultural, histórica y económica (González Bernáldez, 1987; Williams, 1999).

El inventario de los humedales de una determinada región, así como su clasificación tipológica, son pasos imprescindibles para el reconocimiento social, la elaboración de planes y programas de conservación y gestión medioambiental (Finlayson, 1999). Por este motivo, tanto a escala nacional como regional, existen numerosos estudios y registros de humedales (Dantín, 1940; Pardo, 1948; Vélez, 1984; Casado y Montes, 1995; Montes y Martino, 1987; Vega Pozuelo, 2002; Junta de Andalucía, 2005).

Para el caso de Andalucía, marco territorial general de nuestros fines y propuestas, ya se cuenta con un Inventario de Humedales (IHA) y un Plan Andaluz de Humedales (PAH). Sin embargo, tales inventarios y estrategias adolecen aún de una exhaustiva catalogación de los humedales de carácter temporal; lo que nos ha llevado a plantear, como proyecto doctoral, una metodología y propuesta de catalogación de humedales que, a lo ya inventariado, sume la verdadera riqueza de estos ejemplos paisajísticos. Y para tal propósito hemos elegido parte de la cuenca del Medio Guadalquivir, un sector que verdaderamente se caracteriza por su localización central en el contexto del territorio regional.

A pesar de la incuestionable importancia que hoy se atribuye a tales espacios, especialmente desde la perspectiva ambiental, prácticamente en todos los casos existe un deterioro significativo de sus condiciones eco-culturales, cuyas principales causas se encuentran en el desconocimiento de su existencia, la falta de sensibilidad pública ante la necesidad de proteger estos espacios, su insalubre consideración y el interés económico de la puesta en explotación de nuevas tierras con fines agrícolas, construcción de infraestructuras, rurubanización, etc. Circunstancias que, indudablemente, contribuyen de forma evidente al desarrollo de tensiones territoriales, 
Vega-Pozuelo, R., Torres-Márquez, M. y Naranjo-Ramírez, J. (2017): “Recursos cartográficos y geohistóricos para el inventario de humedales temporales y desecados mediterráneos”, GeoFocus (Artículos), no 19, p. 151-179. ISSN: 1578-5157 http://dx.doi.org/10.21138/GF.540

paisajísticas, económicas y patrimoniales con desiguales resultados, aunque siempre condicionando el presente y el futuro de estos humedales.

Teniendo en cuenta todo lo anterior, en este trabajo trataremos de exponer y de valorar las fuentes de información geográficas y, sobre todo, cartográficas, actuales e históricas, que son útiles para el trabajo de gabinete y el examen de campo en la realización de un inventario y estudio del paisaje de los humedales temporales; un inventario que, por otro lado, complete el Inventario de Humedales de Andalucía (IHA) y aporte una revisión metodológica de futuras catalogaciones o reconocimientos. También detallaremos las posibilidades de acceso a la información y la calidad de las fuentes gráficas como herramientas para el examen e inventario de los humedales y salinas continentales, considerando de forma especial su significado para un área de análisis muestral que se inscribe en el Medio Guadalquivir. Unas herramientas que, por supuesto, deberían enriquecerse con documentos de archivo, o incluso con la suma de la memoria histórica de los ciudadanos.

\section{2.- Área de estudio}

La zona seleccionada para el estudio, el Medio Guadalquivir, se localiza en el sur de España y engloba el territorio incluido entre el río Guadalquivir y las cuencas vertientes oeste y este respectivamente de dos de sus principales afluentes meridionales: el río Guadalbullón (provincia de Jaén) y el Genil, en el límite administrativo de las provincias de Córdoba y Sevilla (Figura 1). Este amplio sector, aunque ambicioso en extensión, agrupa una plural casuística que, por otra parte, nos permitirá seleccionar una serie de casos ilustrativos en los que, sin descuidar la escala y la dimensión territorial de nuestro proyecto, poder ejemplificar el método, el estudio y los resultados del análisis propuesto y potencialmente extrapolables al conjunto del territorio esbozado o incluso al conjunto de Andalucía (Figura 1).

Desde la perspectiva territorial y administrativa, el área integra un total de 89 términos municipales ${ }^{1}$, repartidos entre las cuatro provincias que confluyen en esta centralidad geográfica e hidrográfica del territorio andaluz ${ }^{2}$ (Figura 2).

El marco geológico de la zona de estudio presenta una configuración asimétrica, con un acercamiento acentuado al zócalo hespérico, por el norte; y una amplia presencia de las formaciones neógenas en el centro y sur del ámbito. De este modo, se nos ofrece en la actualidad como un medio predominantemente cenozoico de materiales terciarios y cuaternarios (eminentemente arcillosos), flanqueados por contextos paleozoicos septentrionales y potentes estratos

\footnotetext{
${ }^{1}$ Aguilar de la Frontera, Alcalá la Real, Alcaudete, Algarinejo, Almedinilla, Almodóvar del Río, Andújar, Arjona, Arjonilla, Baena, Benamejí, Bujalance, Cabra, Campillo de Arenas, Cañete de las Torres, Carcabuey, Cárcheles, La Carlota, El Carpio, Castillo de Locubín, Castro del Río, Cazalilla, Colomera, Córdoba, Doña Mencía, Écija, Encinas Reales, Escañuela, Espejo, Espelúy, Estepa, Fernán-Núñez, Frailes, Fuensanta de Martos, Fuente Palmera, FuenteTójar, Fuerte del Rey, Guadalcázar, La Guardia de Jaén, Higuera de Calatrava, Hornachuelos, Illora, Iznájar, Jaén, Jamilena, Lahiguera, Loja, Lopera, Lucena, Luque, Marmolejo, Martos, Mengíbar, Moclín, Montalbán de Córdoba, Montefrío, Montemayor, Montilla, Montillana, Montoro, Monturque, Moriles, Noalejo, Nueva Carteya, Palma del Río, Pedro Abad, Pegalajar, Pinos Puente, Porcuna, Posadas, Priego de Córdoba, Puente Genil, La Rambla, Rute, San Sebastián de los Ballesteros, Santaella, Santiago de Calatrava, Torre del Campo, Torredonjimeno, Valdepeñas de Jaén, Valenzuela, La Victoria, Villa del Río, Villafranca de Córdoba, Villanueva de la Reina, Villardompardo, Los Villares, Zagra y Zuheros.

${ }^{2}$ Córdoba, Granada, Jaén y Sevilla.
} 
Vega-Pozuelo, R., Torres-Márquez, M. y Naranjo-Ramírez, J. (2017): “Recursos cartográficos y geohistóricos para el inventario de humedales temporales y desecados mediterráneos”, GeoFocus (Artículos), no 19, p. 151-179. ISSN: 1578-5157 http://dx.doi.org/10.21138/GF.540

carbonatados al sur; todo ello remozado y condicionado por las presiones alpinas del conjunto Bético y los posteriores procesos de erosión y sedimentación postalpinas.

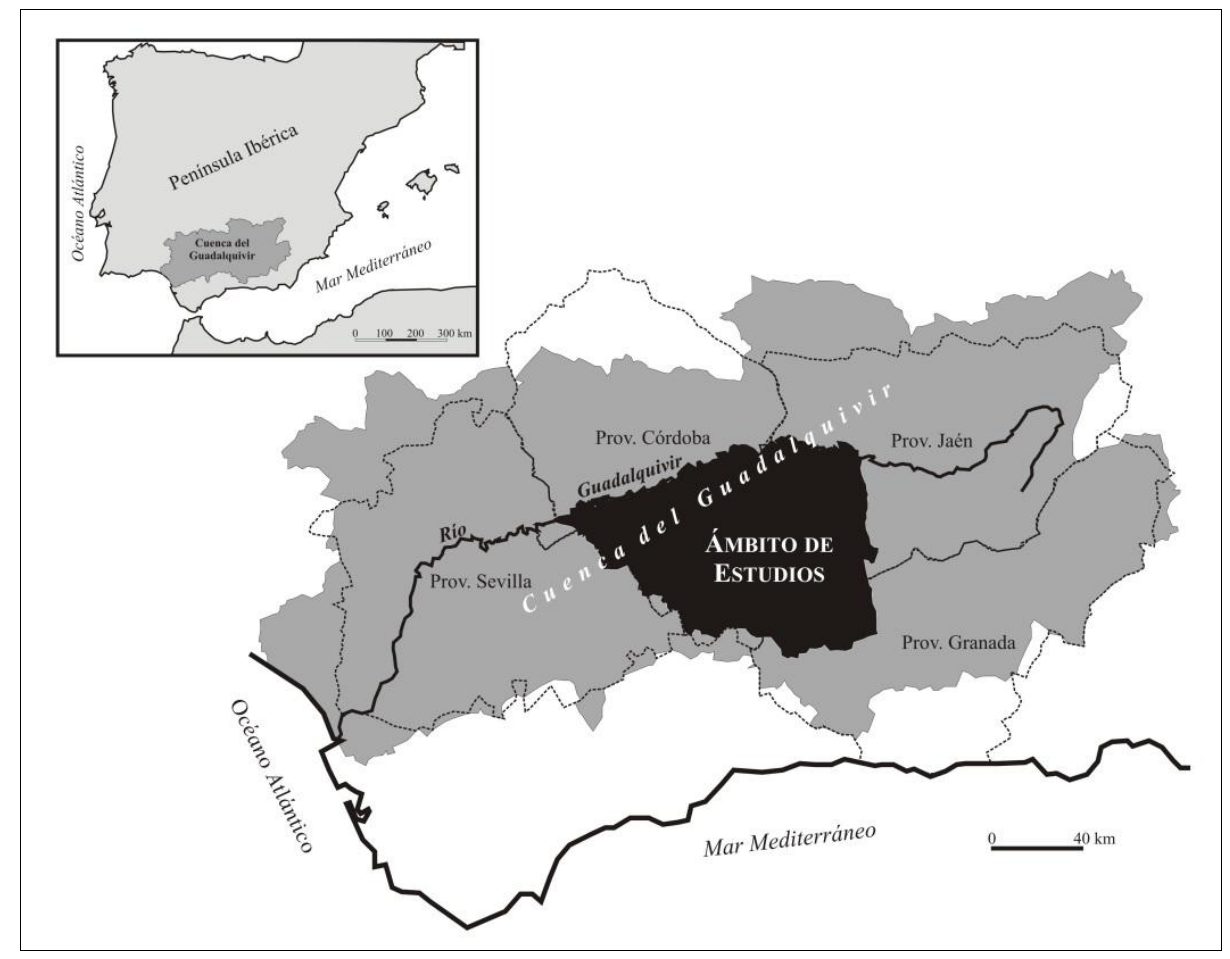

Figura 1. Localización de la zona de estudio.

Fuente: Elaboración propia.

En cuanto al clima, las condiciones mediterráneas de este territorio, matizadas por cierto grado de continentalidad, son consideradas la base o sustrato bioclimático sobre el que se construye el paisaje. En este sentido, las acciones más permanentes, capaces de fijar incluso el dibujo de los campos, derivan de una adaptación humana a las condicionantes climáticas (Meynier, 1968).

El análisis de situaciones atmosféricas dinámicas y el estudio de diagramas ombrotérmicos permiten contextualizar los humedales temporales mediterráneos que aquí existen, en un medio natural singular, con una cobertura vegetal modificada por la acción secular de sucesivas generaciones (Naranjo Ramírez, 2013), que han actuado sobre un relieve contrastado y que han creado unos suelos agrarios muy diferentes a los naturales, pero muy dependientes de su naturaleza y composición (Bermejo, Cáceres y Moreira, 2011; Programa de producción de información sobre Usos y Coberturas Vegetales del Suelo). 


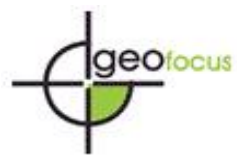

Vega-Pozuelo, R., Torres-Márquez, M. y Naranjo-Ramírez, J. (2017): “Recursos cartográficos y geohistóricos para el inventario de humedales temporales y desecados mediterráneos”, GeoFocus (Artículos), no 19, p. 151-179. ISSN: 1578-5157 http://dx.doi.org/10.21138/GF.540

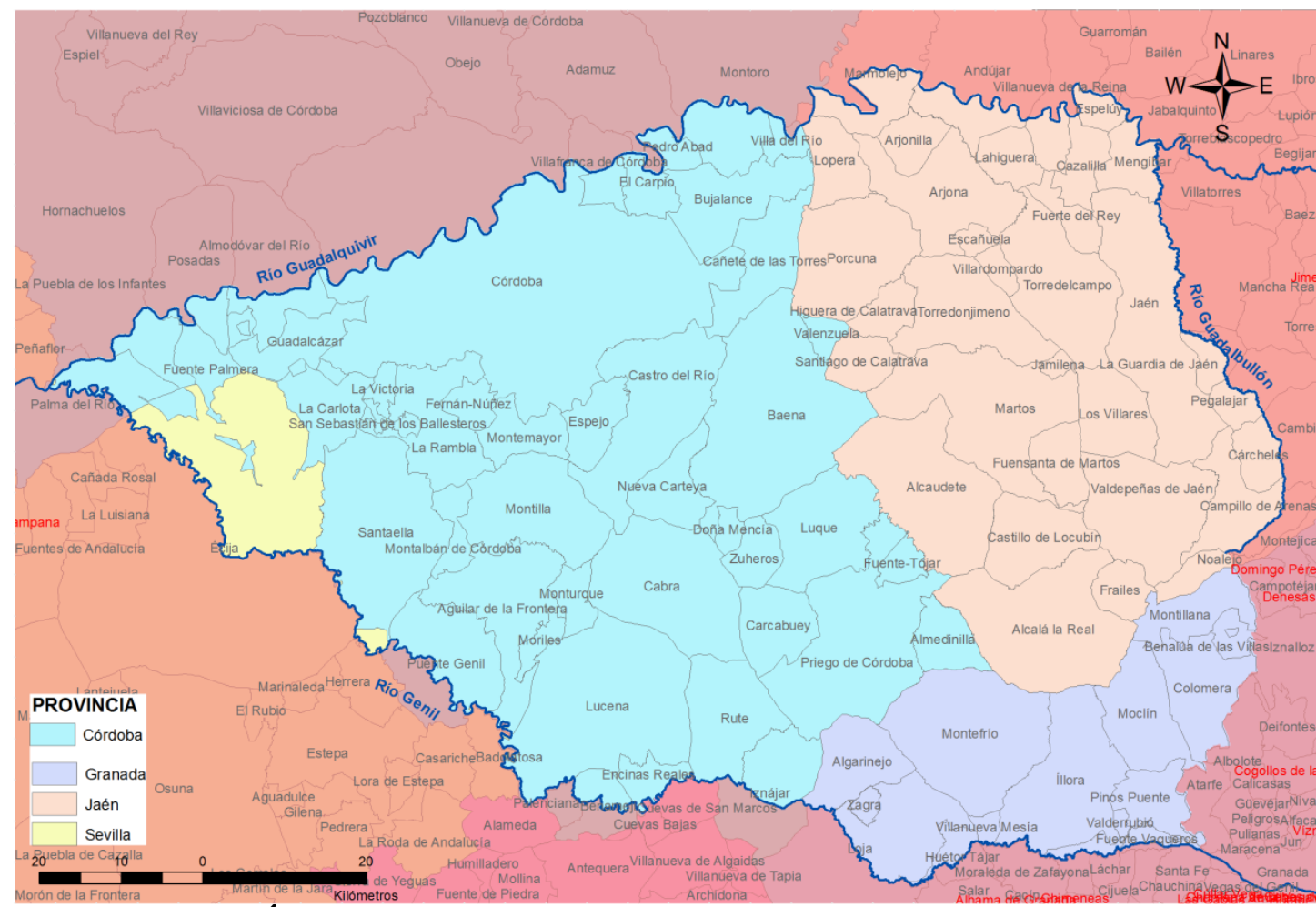

Figura 2. Ámbito administrativo del Medio Guadalquivir y área de estudio.

Fuente: Elaboración propia.

El valle medio del Guadalquivir se caracteriza por su clima cálido, con promedios anuales entre $16^{\circ} \mathrm{C} \mathrm{y} 19^{\circ} \mathrm{C}$. El verano, diferenciado por el calor y la aridez, es cronológicamente largo y caluroso, rebasando las máximas con frecuencia de los $40^{\circ} \mathrm{C}$; mientras que los promedios de julio-agosto se enmarcan entre $24^{\circ} \mathrm{C}$ y $28^{\circ} \mathrm{C}$. El invierno es suave y las medias de enero sólo descienden hasta $10^{\circ} \mathrm{C}-8^{\circ} \mathrm{C}$; las heladas varían entre 5 y 25 anuales dependiendo de la altitud, aunque con frecuencia espacios en situación topográfica deprimida, por efecto de la inversión térmica, sufren de las heladas en grado superior a los espacios más elevados. En cualquier caso, sin alcanzar ordinariamente los meses comprendidos entre abril y octubre. La oscilación anual alcanza los $19^{\circ} \mathrm{C}$, igualando los valores del centro peninsular (Pita, 2003).

Para la realización del inventario de humedales que estamos desarrollando se ha comenzado por utilizar la definición de "humedal" más acorde con los objetivos de este trabajo. Se ha tomado la definición ofrecida por González Bernáldez (1988), quien, en términos generales, estable que los humedales son cualquier anomalía hídrica positiva en el paisaje, de origen natural o artificial, que no es ni un río ni un lago, y que se caracteriza por presentar comunidades biológicas o usos característicos que la diferencian del entorno (DGOH, 1991); y, al igual que hizo Guerrero Ruiz, Ortega González y Parra (2003), se han incluido los desaparecidos y/o desecados, debido a que en muchas ocasiones pueden ser recuperados, pese a presentar un estado de degradación elevadísimo o incluso, como decimos, su total extinción.

Además, en nuestra propuesta de inventario se incluyen las salinas continentales o de interior situadas en la zona, los humedales de origen artificial, e incluso, en la medida de lo posible, los conocidos como criptohumedales (humedales ocultos o poco aparentes) (NaranjoRamírez y Vega-Pozuelo, 2015). 
Vega-Pozuelo, R., Torres-Márquez, M. y Naranjo-Ramírez, J. (2017): “Recursos cartográficos y geohistóricos para el inventario de humedales temporales y desecados mediterráneos”, GeoFocus (Artículos), no 19, p. 151-179. ISSN: 1578-5157 http://dx.doi.org/10.21138/GF.540

\section{3.- Recursos y documentos cartográficos como base de la propuesta metodológica}

A continuación, se expondrán las fuentes más representativas para la realización del inventario de humedales que estamos realizando en nuestro ámbito de estudio. Nuestra propuesta, como es obvio, establece como necesario el vaciado de una amplia colección de fuentes actuales, históricas, geográficas y de otra matriz, que mejor y más detalladamente favorezca el desarrollo de una identificación exhaustiva de la rica, pretérita y presente, red de humedales mediterráneos del área de estudio. Unos recursos y documentos que, sin ser específicos de nuestro ámbito, deberían utilizarse igualmente para otros territorios, pues sólo de esta forma cabe el afloramiento de una compleja y todavía mal conocida red de esas anomalías hídricas positivas. Seguidamente hacemos mención expresa de algunos de estos documentos y fuentes, de sus características y accesibilidad para nuestra investigación.

\section{1.- Minutas cartográficas}

Otra de las fuentes valiosas y necesarias para nuestros propósitos es el análisis de la documentación y cartografía histórica asociada a la creación de la primera serie topográfica nacional. Las observaciones preliminares de la red geodésica se iniciaron en 1854. En 1858 se inició el levantamiento topográfico que, entre otros fines, debía servir tanto para la formación del Mapa de España a escala 1:50.000, como para la formación del Catastro.

El Instituto Geográfico se creó en el año 1870 y supuso el inicio decidido e institucional de cartografiar por primera vez la superficie de España con detalle (Urteaga y Nadal, 2001). Para ello se dan unas instrucciones técnicas precisas y se especifica que la escala definitiva a emplear sea la 1:50.000, si bien los trabajos topográficos que habían de servir de base, mediante el levantamiento de las conocidas minutas, se realizaron utilizando la escala 1:25.000. La edición del Mapa de España se inició en 1875, cuando fueron estampadas las hojas de Madrid (559) y Colmenar Viejo (534). En Andalucía, afectando al ámbito geográfico de este trabajo, la primera provincia en la que se comienzan los trabajos topográficos y cartográficos será Córdoba (Ruiz Morales, 2005), extendiéndose a lo largo de varias décadas, pues en 1940 se efectúa el último de ellos para la provincia cordobesa (Torres-Márquez, 2016). Resulta, al respecto, muy interesante el estudio realizado por un equipo de geógrafos de Jaén, principalmente sobre cuestiones relacionadas con el olivar (Moya-García, Cuesta-Aguilar y Sánchez-Martínez, 2016), pues en él se plasma la importancia de esta fuente como testimonio de la expansión olivarera en la provincia a partir de finales del XIX y principios del XX, así como el protagonismo previo del mismo cultivo como resultado de los procesos desamortizadores previos. $\mathrm{Y}$ al citado estudio se añade la importancia que tales minutas adquieren, por ejemplo, como herramientas para identificar el hábitat rural tradicional como recurso cartográfico de referencia para la triangulación a pequeña escala, mediciones y definición de lindes municipales (Torres-Márquez, 2016).

Las minutas cartográficas son los documentos previos a la realización del Mapa Topográfico Nacional, y cubren, gracias a un prolijo trabajo de campo, la superficie del territorio nacional (Figura 3). Suelen incorporar una serie de altimetría, una de planimetría y otra conjunta, aunque habitualmente tales trabajos ofrecen cronologías distantes, pues, a los propósitos cartográficos, se irían sumando objetivos catastrales y fiscales que, por otra parte, dilataron temporalmente la ejecución de los trabajos y obligaron a desarrollar diversas versiones o actualizaciones de un mismo territorio representado. Estos documentos están elaborados y organizados por términos municipales, y en ellos los humedales identificados figuran siempre con sus 


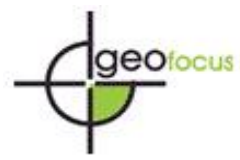

Vega-Pozuelo, R., Torres-Márquez, M. y Naranjo-Ramírez, J. (2017): “Recursos cartográficos y geohistóricos para el inventario de humedales temporales y desecados mediterráneos”, GeoFocus (Artículos), no 19, p. 151-179. ISSN: 1578-5157 http://dx.doi.org/10.21138/GF.540

nombres y con la extensión de su superficie. Sin embargo, no existe ninguna referencia al régimen de propiedad de los mismos, pero resulta interesante que en numerosas ocasiones se realizan rectificaciones en distintas fechas en los mismos documentos, hasta los años 60 (Sastre Domingo \& Yuste Galán, 2004). Unas rectificaciones que, en lo relativo a los humedales, suelen actualizar su presencia o no temporal, la afección de sus contornos, las modificaciones provocadas por roturaciones o por la construcción y reforma de caminos y accesos.

Estas minutas cartográficas conllevan también importantes trabajos previos como fueron las labores geodésicas o los deslindes y amojonamientos de los términos municipales. Para su realización se emplearon unos cuadernos de campo donde los topógrafos realizaban unos croquis muy detallados, situando los humedales por referencia a puntos visibles, y anotando los hitos más significativos del paisaje, ya fuesen cerros enhiestos, viviendas rurales, campanarios de parroquias, puentes, caminos, etc. (Torres-Márquez, 2016).
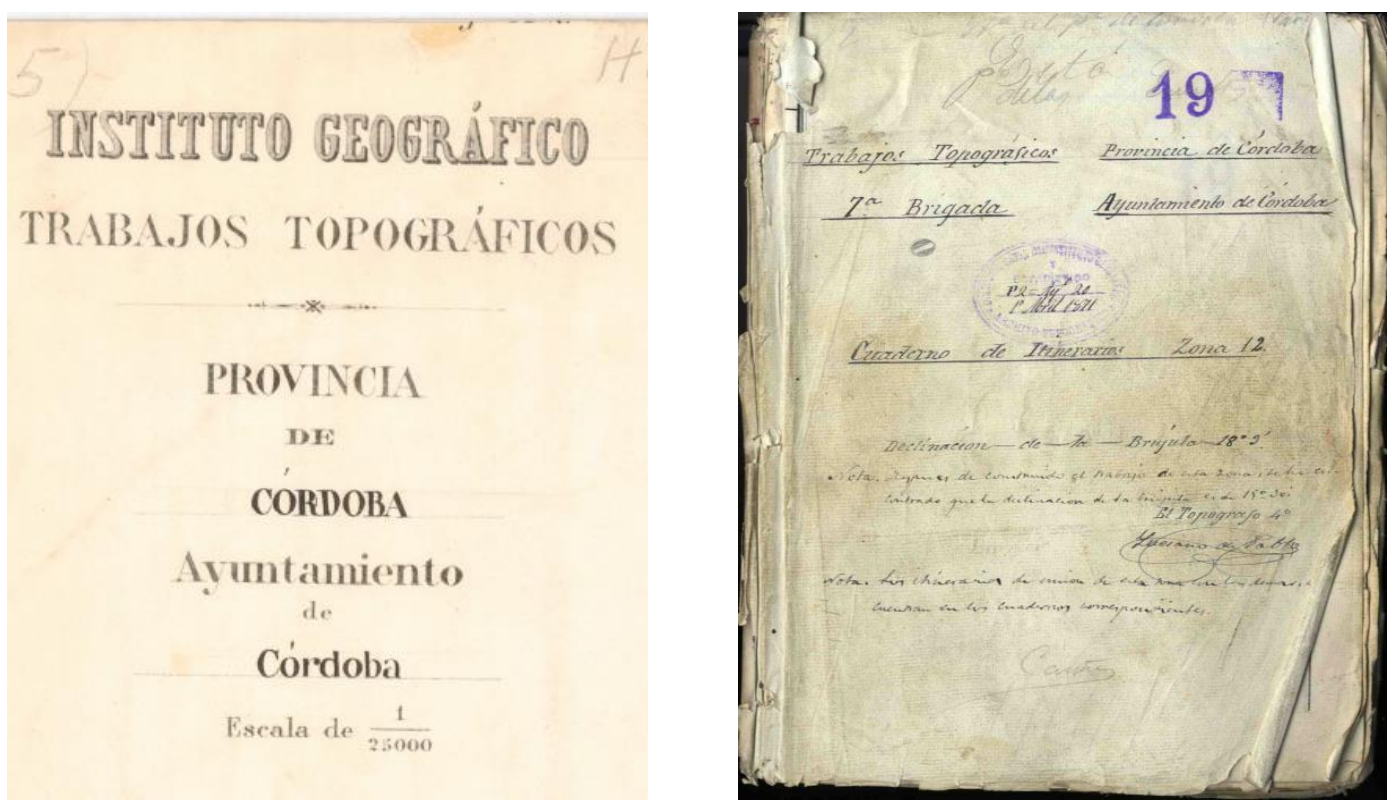

Figura 3. Portadas de minuta cartográfica y de cuaderno de campo del término municipal de Córdoba realizadas en abril de 1871.

Fuente: Centro de Descargas del IGN en http://centrodedescargas.cnig.es/CentroDescargas/index.jsp [abril de 2017].

De estos cuadernillos, además de poder obtener más detalle de dónde se sitúa o situaba el humedal, podemos conseguir una aproximación de la morfometría del mismo en aquella época.

A título de ejemplo podemos mostrar una de las minutas altimétricas del término municipal de Lucena (Córdoba), aquella en la se representa el conjunto de las actuales lagunas de los Jarales, Amarga, etc (Figura 4). El documento se realizó en 1893 y, además de proporcionar una rica información topográfica y toponímica, nos sitúa con precisión la laguna Amarga, no representa la más conocida en la actualidad laguna de los Jarales y, como elemento sobresaliente, se incorpora con gran claridad planimétrica la existencia de las Salinas del Marqués del Campo de Aras (Figura 4), situadas por entonces en las inmediaciones del cortijo homónimo y que, en la actualidad, han desaparecido baja la expansión periurbana y rururbana de la localidad lucentina. 


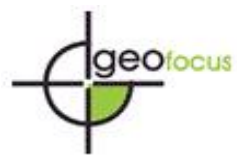

Vega-Pozuelo, R., Torres-Márquez, M. y Naranjo-Ramírez, J. (2017): “Recursos cartográficos y geohistóricos para el inventario de humedales temporales y desecados mediterráneos”, GeoFocus (Artículos), no 19, p. 151-179. ISSN: 1578-5157 http://dx.doi.org/10.21138/GF.540

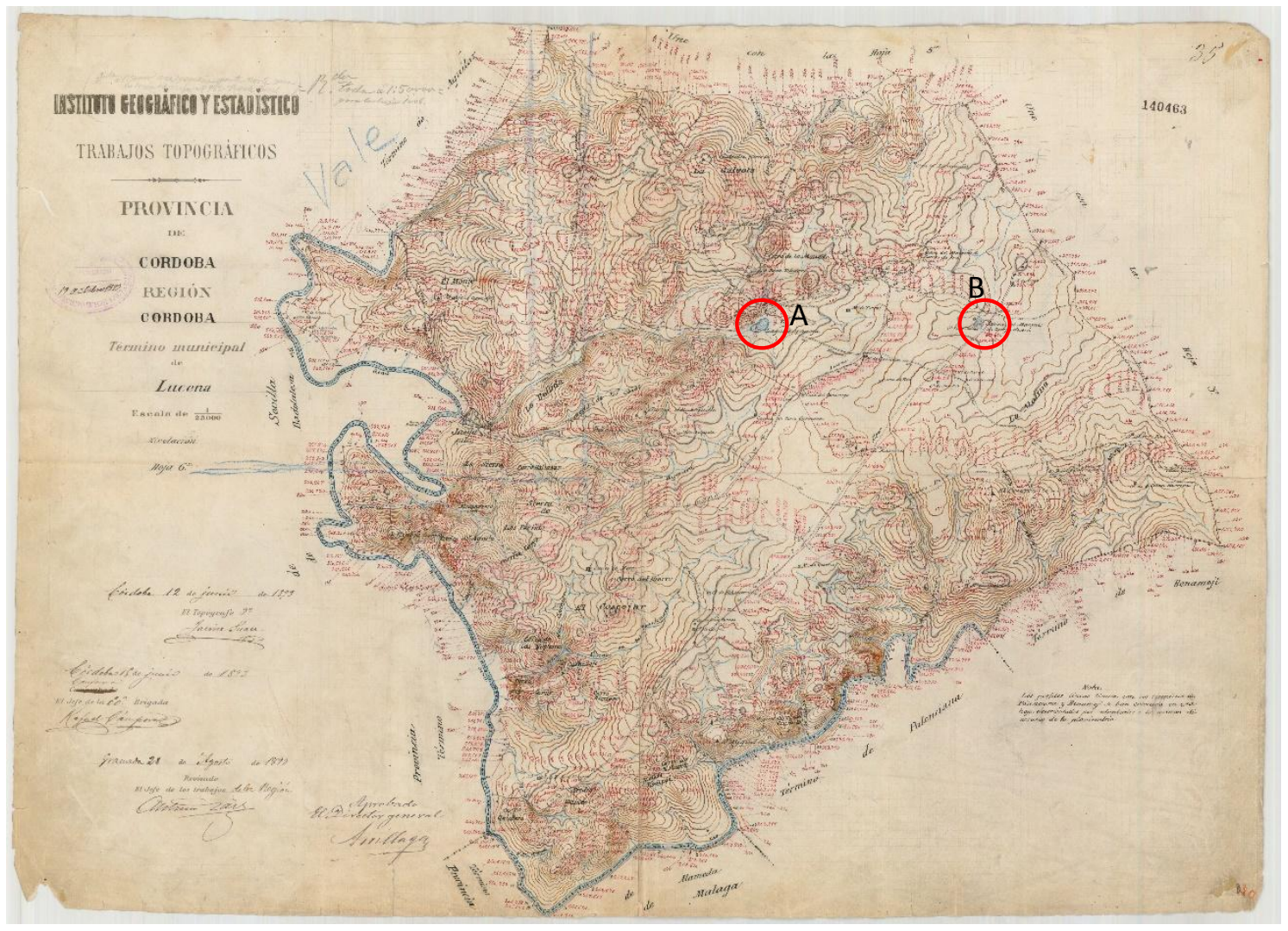

Figura 4. Minuta cartográfica de parte del término municipal de Lucena (Córdoba), realizada en 1893. En ella se representan con claridad la laguna Amarga (A) y la desaparecida Salina del Marqués del Campo de Aras (B).

Fuente: Centro de Descargas del IGN en http://centrodedescargas.cnig.es/CentroDescargas/index.jsp [abril de 2017].

Tanto las minutas cartográficas como los cuadernillos de campo y deslindes de términos se pueden consultar en el Archivo del Instituto Geográfico Nacional, situado en su sede de Madrid, calle General Ibáñez de Íbero, 3. Se pueden solicitar los mapas también por correo electrónico, y posee un servicio de reproducciones. Su página web es www.ign.es. Están incorporados al Centro de Descargas del $\mathrm{CNIG}^{3}$. Así mismo hemos encontrado algunas versiones, posteriores, de estos trabajos topográficos en el Instituto de Historia y Cultura Militar (Paseo Moret, $\mathrm{n}^{\mathrm{o}}$ 3, Madrid).

\section{2.- Mapa topográfico Nacional}

En las instrucciones antes mencionadas, se especifica que los mapas obtenidos se publicarían a escala 1:50.000 y divididos en hojas de 20 minutos de base por 10 minutos de altura en el sentido de los meridianos. Éste es el comienzo de la serie de cartográfica que conocemos hoy día con la denominación editorial de Mapa Topográfico Nacional 1:50.000. Normalmente la

${ }^{3}$ http://centrodedescargas.cnig.es/CentroDescargas/index.jsp [último acceso: 20/04/2017]. 
Vega-Pozuelo, R., Torres-Márquez, M. y Naranjo-Ramírez, J. (2017): “Recursos cartográficos y geohistóricos para el inventario de humedales temporales y desecados mediterráneos”, GeoFocus (Artículos), no 19, p. 151-179. ISSN: 1578-5157 http://dx.doi.org/10.21138/GF.540

primera edición fue muy similar a los trabajos topográficos previos ${ }^{4}$, por lo que prácticamente, al menos para una primera investigación, pueden ser útiles, pues gozan de un detalle planimétrico y toponímico extraordinario, sólo posible gracias al trabajo de campo llevado a cabo por los topógrafos (Figura 5). La primera hoja se publicó en 1875, mientras que la última se demoró a 1968 (Sastre Domingo \& Yuste Galán, 2004).

Toda la serie oficial del IGN se puede descargar gratuitamente desde el Centro de Descargas del Centro Nacional de Información Geográfica ${ }^{5}$. También se pueden consultar la primera serie de estos mapas mediante visualizadores de WMS, como es el caso de la aplicación online Iberpix del mismo IGN ${ }^{6}$.

En el caso andaluz se puede adquirir el CD "Cartografía de un siglo. Andalucía en la primera edición del Mapa Topográfico Nacional 1:50.000" que contiene la primera edición para toda la serie.

Al menos en el caso del Medio Guadalquivir, las distintas ediciones del mapa oficial del IGN, apenas introducen variaciones con respecto a la primera hasta la de 1979.

A partir de los años 70 van desapareciendo los nombres de los humedales de menor entidad, y los mapas topográficos a escala 1:50.000 se vuelven prácticamente inútiles para encontrar charchas y salinas. Bien por iniciarse un progresivo proceso de limpieza toponímica de las diferentes ediciones topográficas, o bien por el empleo de técnicas por restitución fotogramétrica que, sin un paralelo trabajo de campo, irán reduciendo el detalle y el análisis directo del territorio, lo que se traducirá en una creciente limpieza informativa de la cartografía oficial nacional. Una limpieza informativa que, por supuesto, también afectará a las masas de aguas y los humedales, aunque a veces sea complejo desentrañar si la desaparición del tal o cual humedal en la cartografía topográfica se ha debido a la modificación técnica o a los criterios editoriales del mapa, o sencillamente se ha extinguido debido a procesos de desecación, roturación, etc.

\footnotetext{
${ }^{4}$ Los mapas previos son, fundamentalmente, la cartografía histórica moderna (los mapas parcelarios más antiguos) y las minutas municipales del Mapa Topográfico Nacional de España 1:50.000, del Instituto Geográfico Nacional, generalmente del último cuarto del siglo XIX o del primero del siglo XX.

5 http://centrodedescargas.cnig.es/CentroDescargas/index.jsp [último acceso: 20/04/2017].

${ }^{6}$ http://www.ign.es/iberpix2/visor/ [último acceso: 20/04/2017]
} 


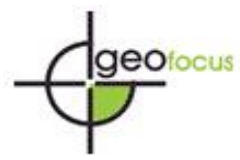

Vega-Pozuelo, R., Torres-Márquez, M. y Naranjo-Ramírez, J. (2017): “Recursos cartográficos y geohistóricos para el inventario de humedales temporales y desecados mediterráneos", GeoFocus (Artículos), no 19, p. 151-179. ISSN: 1578-5157 http://dx.doi.org/10.21138/GF.540

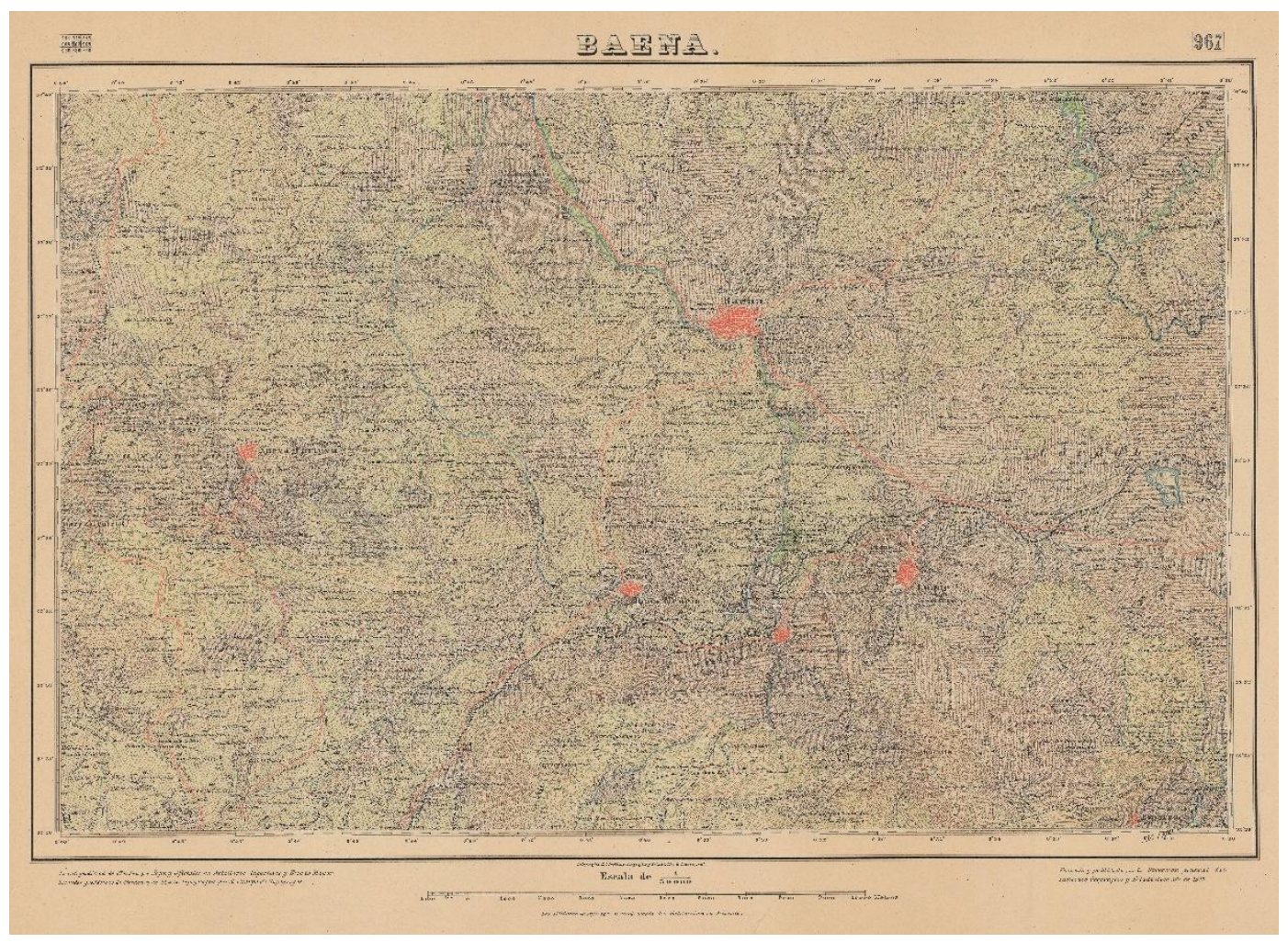

Figura 5. Mapa Topográfico 1:50.000 de Baena (Córdoba) (hoja 967) del año 1905.

Fuente: Instituto Geográfico Nacional, disponible en

http://centrodedescargas.cnig.es/CentroDescargas/index.jsp [último acceso: 20/04/2017].

\section{3.- Cartillas evaluatorias del Catastro por masas de cultivo}

La principal fuente de ingresos de la Hacienda española era la Contribución Territorial que se repartía en base al injusto sistema de los Amillaramientos. El catastro parcelario constituiría el instrumento básico sobre el que apoyar una política fiscal más justa y eficiente. La ley de la Medición del Territorio, aprobada en las Cortes en 1859, vinculó el levantamiento del mapa de España con el establecimiento del Catastro general. Estas tareas fueron encomendadas a la Comisión de Estadística General del Reino (Muro, Urteaga y Nadal, 1996; Urteaga y Nadal, 2001).

En el año 1895 se promulgó la Ley de 17 de julio, de rectificación de los Amillaramientos, que tuvo su desarrollo reglamentario mediante Real Decreto de 14 de agosto. Este marco jurídico determinó la realización de un levantamiento de un catastro por masas de cultivo y clases de terreno, con el objetivo de investigar la presunta ocultación en las declaraciones de los rendimientos de las tierras.

En 1906 se publica una nueva Ley del Catastro con los mismos fines.

Estos trabajos incluyen también itinerarios con brújula, y planos escala 1:25.000 que básicamente son los mismos que los citados para la elaboración del Mapa Topográfico Nacional. A veces también incluyen una relación de caminos, humedales, ríos y arroyos con sus an- 
Vega-Pozuelo, R., Torres-Márquez, M. y Naranjo-Ramírez, J. (2017): “Recursos cartográficos y geohistóricos para el inventario de humedales temporales y desecados mediterráneos”, GeoFocus (Artículos), no 19, p. 151-179. ISSN: 1578-5157 http://dx.doi.org/10.21138/GF.540

chos medios (Fernández Escorial, 2005), e incorporan, dada su vocación catastral y fiscal, mucha otra documentación sobre la actividad agrícola, los usos y aprovechamientos del suelo.

En 1896 se publica el Reglamento General para la Rectificación de Cartillas Evaluatorias de la Riqueza Rústica y Pecuaria, en la Gaceta de Madrid no 366 (31 de diciembre). En este reglamento se especifica que, para formar los bosquejos planimétricos, "comprenderán en cada uno de estos la determinación de sus líneas, hitos jurisdiccionales, el curso de los ríos, canales de navegación y de riego, los arroyos, las vías de comunicación, sean ferrocarriles, tranvías, carreteras o caminos rurales, siempre que estos últimos sean de servicio público y constante".

Igualmente, la Ley de 27 de marzo de 1900 (artículo $4^{\circ}$ ) dispone el establecimiento del registro fiscal de la propiedad en todas las capitales de provincia, excepto en las Vascongadas y Navarra (BOE, 1900). Establece que "constituirá el catastro, por masas de cultivo y clases de terreno de cada término municipal, un plano geométrico del mismo... y en los que se fijarán necesariamente ... las vías de comunicación, sean ferrocarriles, tranvías, carreteras, caminos vecinales, cañadas, descansaderos, etc."

Estos planos y sus documentos catastrales anejos se suelen conservar en los Archivos Históricos Provinciales, al menos para el caso de la Comunidad Autónoma de Andalucía. Sin embargo, este catastro no llegó a realizarse en toda España, sino sólo en el sur, paralizándose sus trabajos en 1925 (Urteaga, 2008; Torres-Márquez, 2012).

Previo a éste, hubo otro proyecto de catastro, de mucho mayor detalle, obra de Francisco Coello, pero que sólo se realizó en la provincia de Madrid, entre los años 1859 y 1869. Según el Reglamento general para la formación de planos parcelarios, aprobado en febrero de 1862 el levantamiento tenía dos metas: primero ejecutar la parte topográfica del mapa general del país, ligándola a los resultados geodésicos; y, segundo, obtener la representación y medición parcelaria, es decir, lindes y superficies heredables (Urteaga y Nadal, 2001). 


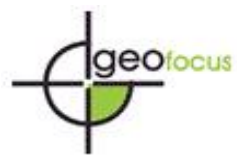

Vega-Pozuelo, R., Torres-Márquez, M. y Naranjo-Ramírez, J. (2017): “Recursos cartográficos y geohistóricos para el inventario de humedales temporales y desecados mediterráneos”, GeoFocus (Artículos), no 19, p. 151-179. ISSN: 1578-5157 http://dx.doi.org/10.21138/GF.540

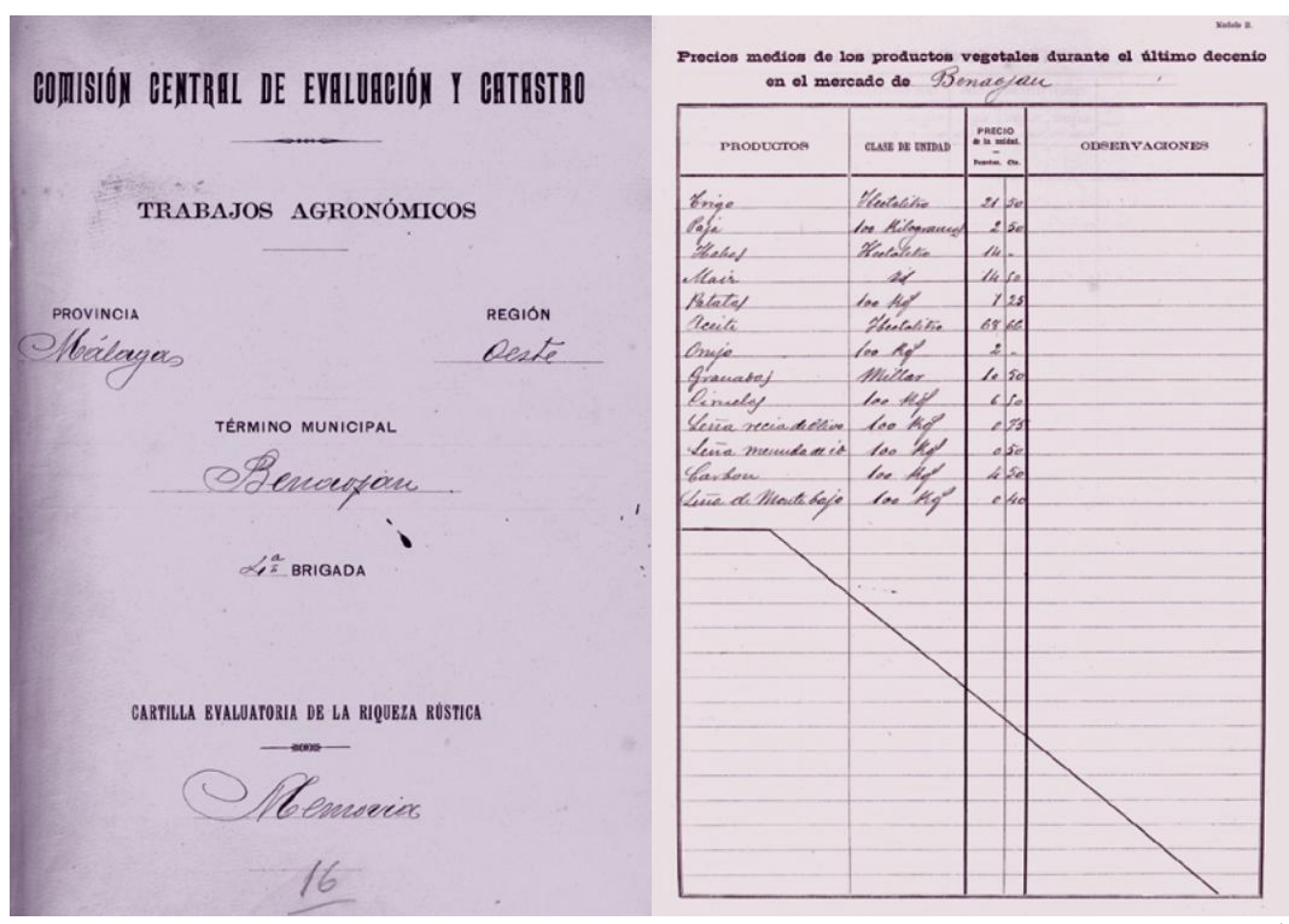

Figura 6. Cartilla evaluatoria del Catastro por masas de cultivo en la provincia de Málaga, término de Benaoján.

Fuente: Archivo Histórico Provincial de Málaga.

\section{4.- Catastro Nacional Topográfico Parcelario}

En el año 1925 se decide abandonar los trabajos del catastro por masas de cultivo y se emprende el Catastro Parcelario, cuyos trabajos comienzan en 1928 (Fernández Nieto, 2005). Dependiendo del tamaño de las parcelas catastrales, la escala de la cartografía varía entre 1:2.000 y 1:10.000, siendo, tanto por la escala como por el método de levantamiento utilizado, mucho más precisa que los mapas anteriores.

La elaboración de este catastro se interrumpió varias veces entre los años 1932 y 1941, volviéndose definitivamente a retomar por Orden Ministerial de 16 de diciembre de 1941. Poco a poco se van utilizando las fotografías aéreas para realizarlo y en 1960 quedó prácticamente acabado (Martínez Laceras, 2000). Aún en el año 1979 se asume esta cartografía como el único parcelario oficial (Berné Valero, Femenia Ribera, \& Aznar Bellver, 2004).

En estos planos los humedales, caminos, arroyos, cañadas, carreteras etc., están señalados con números romanos I, II, III, IV, V y sucesivos, y su presencia representa o equivale a superficies de descuento del polígono catastral (Fernández Nieto, 2005). Se trata, por tanto, de un instrumento excelente, por su precisión, para determinar la ubicación, dimensiones y morfometría de los humedales hoy desecados, o incluso permite examinar cómo han cambiado aquellos humedales que aún subsisten a la presión antrópica (González Bernáldez, 1987). 
Vega-Pozuelo, R., Torres-Márquez, M. y Naranjo-Ramírez, J. (2017): “Recursos cartográficos y geohistóricos para el inventario de humedales temporales y desecados mediterráneos”, GeoFocus (Artículos), no 19, p. 151-179. ISSN: 1578-5157 http://dx.doi.org/10.21138/GF.540

Según las instrucciones para la elaboración del Catastro, de 1942, los humedales y otros lugares como caminos sobre los que, sí existe seguridad de ser públicos, son los que constituyan divisorias de polígonos catastrales. Ya que según dichas instrucciones han de contar con la característica de no estar expuestos a variaciones, no ser terreno de servidumbre y en general presentar garantías de inmutabilidad. Este es el texto de las instrucciones:

"1. Los trabajos topográficos del Catastro parcelario, o primer periodo catastral completo, comprenderán las operaciones de campo y gabinete necesarias para obtener la representación gráfica, posición con respecto a las colindantes y situación geográfica de la parcela, así como su poseedor. Serán por orden los siguientes:"

"Levantamiento del plano perimetral de cada término municipal, con las líneas de sus términos jurisdiccionales, señalando y numerando los hitos o mojones situados en los linderos."

"Dentro del plano de esta línea perimetral se situarán los polígonos topográficos, determinados por las líneas más notables y particularidades permanentes del terreno, como ríos, canales, arroyos, pantanos, puentes, lagunas, vías de comunicación, perímetros de pueblos, grupos de población y edificios."

"Los planos perimetrales de cada término municipal y de los poligonos topográficos en que aquel queda dividido fueron obtenidos en los trabajos para el Mapa Topográfico Nacional, del cual forman parte, con la aproximación exigida por éste".

Capítulo II "Levantamiento de planos parcelarios por polígonos topográficos.

Instrucción $n^{o} 11$ se establece cómo deben delimitarse los polígonos topográficos:

"La situación geográfica y topográfica de los polígonos y la posición relativa de cada uno de éstos respecto a los que le rodean están definidas por los trabajos y datos del Mapa Topográfico Nacional". Es decir, por los planos topográficos de los términos municipales mencionados en la Instrucción $n^{o} 1$.

"Los límites de los polígonos serán siempre líneas permanentes no expuestas a variaciones, como ríos, arroyos, caminos vecinales, carreteras, canales, etc. Se prescindirá por tanto de arroyos cuyo curso pueda variar, caminos rurales que no estén bien determinados y puedan asimismo cambiar de un año para otro, sendas, caminos de servidumbre que puedan perderse $y$, en general, de cuanto no presente garantía de inmutabilidad".

Estos planos se custodian en los Archivos Históricos Provinciales, aunque también parece ser que puede haber copias en los Archivos del Catastro. En el caso de Andalucía, hay gran parte de ellos en la Cartoteca del Instituto de Estadística y Cartografía de Andalucía, pudiéndose descargar, aunque sin estar georreferenciados ${ }^{7}$.

\footnotetext{
${ }^{7}$ http://www.juntadeandalucia.es/institutodeestadisticaycartografia/cartoteca [último acceso: 20/04/2017].
} 
Vega-Pozuelo, R., Torres-Márquez, M. y Naranjo-Ramírez, J. (2017): “Recursos cartográficos y geohistóricos para el inventario de humedales temporales y desecados mediterráneos", GeoFocus (Artículos), no 19, p. 151-179. ISSN: 1578-5157 http://dx.doi.org/10.21138/GF.540

\section{5.- Mapas de la Segunda Guerra Mundial}

El interés geoestratégico del Estrecho de Gibraltar y el posible traslado del teatro de operaciones a la Península Ibérica provocó que, entre los años 1940 y 1944, el Estado Mayor del Ejército Alemán levantara una cartografía de la mayor parte de España basada en la cartografía preexistente, a escala 1:50.000. Se editaron 905 hojas de las 1.114 que componen el Mapa Topográfico Nacional; material que fue, hace algo más de una década, digitalizado y publicado para Andalucía por el Instituto Cartográfico de Andalucía, a partir de los fondos desclasificados existentes en la Biblioteca del Congreso de Washington, la Biblioteca Británica y la Real Sociedad Geográfica de Londres.

Además de la cartografía 1:50.000, el Estado Mayor Alemán levantó cartografía de mayor precisión, pero muy centrada en las costas de Málaga y Cádiz, por ser objetivos bélicos especialmente considerados por el control que ejercían sobre el Estrecho (37 hojas a escala $1: 25.000)$.

Toda esta cartografía, de gran valor para nuestra investigación, se puede consultar mediante WMS, aunque también está disponible en soporte DVD.

Igualmente, por el bando aliado el Army Map Service realizó otra serie cartográfica, entre 1943 y 1951. Esta serie de mapas, para Andalucía, se puede consultar en soporte DVD. En este caso no existe, a la fecha, servicio WMS.

\section{6.- Catastro moderno}

A partir del año 1980 de la elaboración del Catastro se encarga al Centro de Gestión Catastral y Cooperación Tributaria. En los catastros modernos, los elementos de dominio público aparecen con referencia catastral de la parcela comenzada por la cifra 9000. Sin embargo, los humedales no poseen este código debido a que suelen ser, en virtud de lo establecido por la legislación de aguas vigente hasta la fecha, de titularidad privada, aspecto que se modificaría gracias a la ya derogada Ley 29/1985, de 2 de agosto, de Aguas.

No obstante, estos catastros pueden ser consultados en Internet mediante visualizadores, como el propio del Catastro Nacional de España, en el servicio online ${ }^{8}$, o mediante el servicio WMS $^{9}$. Al igual que en el caso del catastro parcelario antiguo, los humedales que son límite de polígonos son los que tenemos la seguridad de que deben ser considerados públicos, ya que los criterios persisten y la legislación al respecto atribuía la titularidad privada a aquellas masas de agua permanentes o temporales incluidas en las parcelas de propiedad que se registraban catastralmente (Figura 6). También se pueden descargar en formato shape desde su página web ${ }^{10}$.

\footnotetext{
${ }^{8}$ http://www.sedecatastro.gob.es [último acceso: 20/04/2017].

9 http://ovc.catastro.meh.es/Cartografia/WMS/ServidorWMS.aspx? [último acceso: 20/04/2017].

${ }^{10}$ http://www.catastro.minhap.es/ayuda/lang/castellano/ayuda_descarga_shape.htm [último acceso: 20/04/2017].
} 


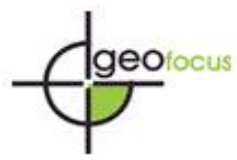

Vega-Pozuelo, R., Torres-Márquez, M. y Naranjo-Ramírez, J. (2017): “Recursos cartográficos y geohistóricos para el inventario de humedales temporales y desecados mediterráneos”, GeoFocus (Artículos), no 19, p. 151-179. ISSN: 1578-5157 http://dx.doi.org/10.21138/GF.540

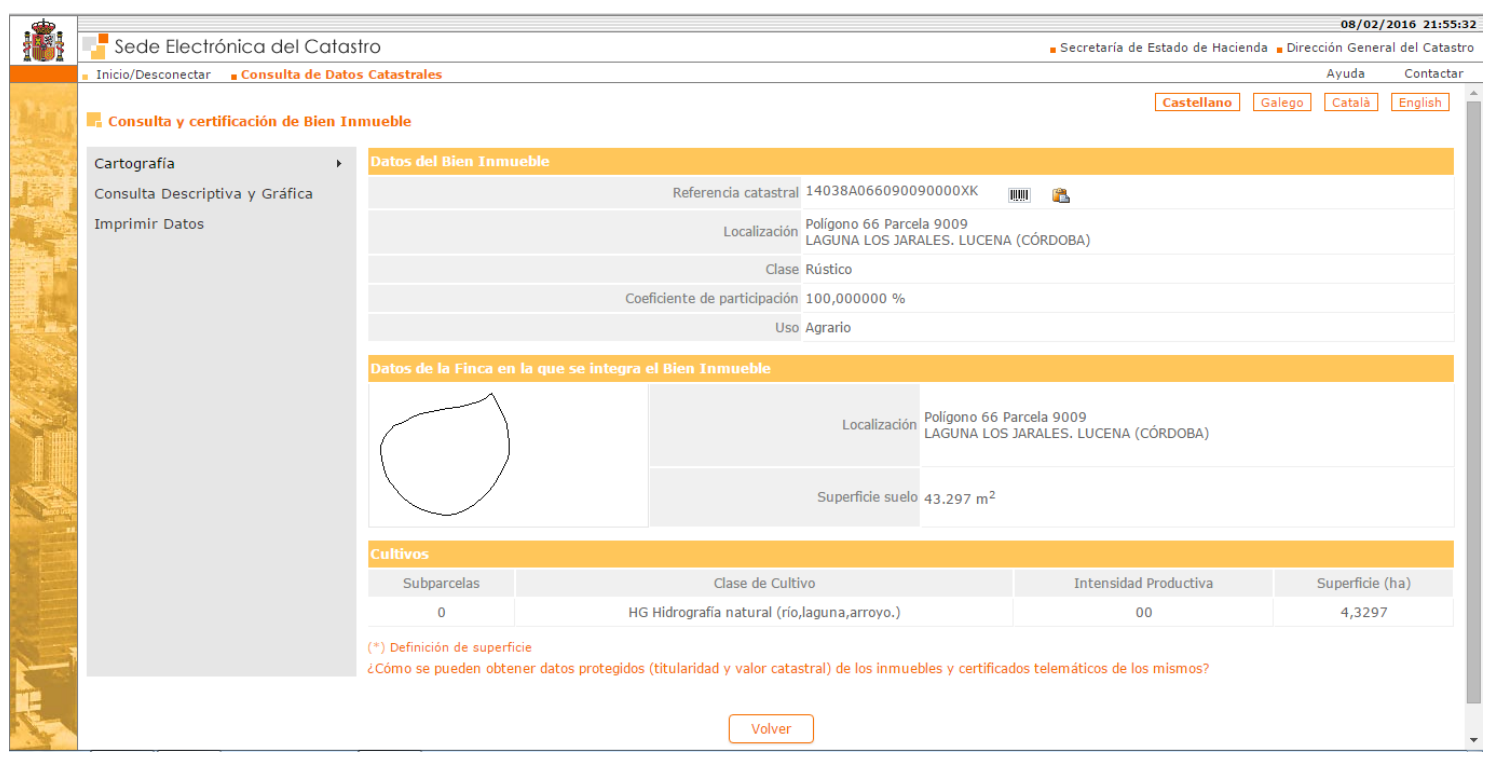

Figura 7. Captura de parcela de catastro moderno de la Laguna de los Jarales (TM Lucena - Córdoba).

Fuente: Dirección General del Catastro. Ministerio de Hacienda.

\section{7.- Fotografias aéreas y ortofotografias.}

Las fotografías aéreas, y especialmente la ortofotografía, son unos instrumentos muy valiosos para localizar humedales de los que no tengamos otras referencias. Además, nos dan una visión fidedigna del estado que posee el humedal en el momento de realización de la fotografía.

En Vales, y otros (2010) se realiza un detallado repaso de los vuelos fotogramétricos que se realizaron en España de forma generalizada. En los años 20 y 30 se realizan los primeros vuelos de zonas determinadas, algunos encargados por confederaciones hidrográficas.

Entre 1946 y 1947 se realiza el primer vuelo nacional. Este vuelo fue desarrollado por el Army Map Service de Estados Unidos y se conoce con el nombre de "Serie A". Su escala aproximada es 1:44.000 y está realizado en película blanco y negro.

Aproximadamente diez años más tarde, entre 1956 y 1957, se realiza un nuevo vuelo, por el mismo servicio americano, llamado "Serie B", en este caso en colaboración con el Instituto Geográfico Nacional y el Servicio Geográfico del Ejército. La escala de este vuelo es 1:33.000 y también está realizado en blanco y negro.

Los originales tanto de la "Serie A" como de la "B" se conservan en el Centro Cartográfico y Fotográfico del Ejército del Aire (CECAF), con sede en la Base Aérea de Cuatro Vientos (Madrid).

Ambas series fotográficas se pueden descargar desde la fototeca del Centro Nacional de Información Geográfica $(\mathrm{CNIG})^{11}$. Sin embargo, en la fototeca del CNIG solo están disponibles

\footnotetext{
${ }^{11}$ http://fototeca.cnig.es/ [último acceso: 20/04/2017].
} 
Vega-Pozuelo, R., Torres-Márquez, M. y Naranjo-Ramírez, J. (2017): “Recursos cartográficos y geohistóricos para el inventario de humedales temporales y desecados mediterráneos", GeoFocus (Artículos), no 19, p. 151-179. ISSN: 1578-5157 http://dx.doi.org/10.21138/GF.540

fotogramas alternos del vuelo de la "serie B". Para localizar toda la información, debe contactarse con REDIAM. Esta fototeca también utiliza servicios WMS para mostrar el fotograma más cercano del ámbito de visualización, pero los fotogramas están georreferenciados de forma aproximada y, debido a las limitaciones de las fotografías, los elementos representados no coinciden geométricamentre con la cartografía base disponible.

La Consejería de Medio Ambiente, en colaboración con el CECAF, llevó a cabo el escaneado de toda la colección de fotogramas y la CMAOT se encargó de la ortorectificación (WMS 14). Esta ortofotografía también se puede descargar desde visor de la REDIAM 16 y desde el Line@ ${ }^{12}$, lo que supone una valiosísima ayuda para situar humedales y evaluar sus dimensiones, formas, georreferenciación, etc.

Tras estos dos primeros vuelos, que son indispensables para saber la situación y el estado de los humedales en la época del catastro, es interesante saber cuál ha sido su evolución hasta la actualidad, sobre todo en el caso de los que aparecen claramente en los años 50 y ya no se muestran ahora en la fotografía aérea, para determinar aproximadamente en qué fecha aproximada han sido desecados. Para ello es posible consultar una gran cantidad de imágenes aéreas. Por ello, además de las ortofotografías publicadas y los vuelos disponibles en la fototeca del CNIG y del IECA, es importante consultar el portal y visor del IECA para conocer la existencia de otros posibles vuelos que se encuentran pendientes o en proceso de publicación.

Para el caso particular de la provincia de Córdoba se dispone de un vuelo fotogramétrico elaborado por la compañía CEFTA, a escala 1:25.000, y realizado por encargo de la Diputación en 1973. A pesar de la escala de cierto detalle utilizada, la utilidad de esta fuente de información para nuestros fines investigadores no es grande, pues carece de la calidad fotográfica deseada. Se puede descargar y visualizar desde la página de la Diputación de Córdoba, alojada en su página web $^{13}$.

El siguiente vuelo de carácter nacional es el llamado Interministerial, aunque conocido como vuelo IRYDA, ya que fue realizado por encargo de los ministerios de Agricultura, Defensa, Hacienda, y el Instituto Geográfico y Catastral, entre los años 1978 y 1986. Se realizó con película blanco y negro, y su escala es 1:18:000. Posee una calidad magnífica para identificar humedales de mediano o pequeño tamaño y cuenta con una ortorectificación realizada por el CMAOT, lo que aumenta exponencialmente su valor documental para nuestro propósito investigador. Las ortofotos resultantes están accesibles en el Visor Descargador y WMS de la Red de Información Ambiental de Andalucía (REDIAM) ${ }^{14}$ y se puede consultar mediante su dirección $\mathrm{WMS}^{15}$.

Para España se puede descargar, pero sin georreferenciar, con ubicación aproximada, desde la fototeca del Centro Nacional de Información Geográfica; pero, como ya se ha mencionado, sólo fotos alternas ${ }^{16}$.

El único vuelo disponible a nivel nacional de la década de los 80 es el vuelo realizado por encargo del Instituto Geográfico y Catastral entre los años 1980 y 1986, con escala 1:33.000. Se

\footnotetext{
${ }^{12} \mathrm{http} / / / \mathrm{www}$.juntadeandalucia.es/institutodeestadisticaycartografia/lineav2/web/ [último acceso: 20/04/2017].

$13 \mathrm{http}: / /$ mapserver.eprinsa.es/visores/Territorial/v 25000 1973/ [último acceso: 20/04/2017].

$14 \mathrm{http://ws041.juntadeandalucia.es/medioambiente/dlidar/index.action} \mathrm{[último} \mathrm{acceso:} \mathrm{20/04/2017].}$

15 http://www.juntadeandalucia.es/medioambiente/mapwms/REDIAM_Ortofoto_BN_1977_83 [último acceso: 20/04/2017].

${ }^{16}$ http://fototeca.cnig.es/ [último acceso: 20/04/2017].
} 


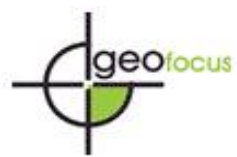

Revista Internacional de Ciencia y Tecnología de la Información Geográfica

International Review of Geographical Information Science and Technology

Vega-Pozuelo, R., Torres-Márquez, M. y Naranjo-Ramírez, J. (2017): “Recursos cartográficos y geohistóricos para el inventario de humedales temporales y desecados mediterráneos”, GeoFocus (Artículos), no 19, p. 151-179. ISSN: 1578-5157 http://dx.doi.org/10.21138/GF.540

puede descargar de la fototeca del Centro Nacional de Información Geográfica; y, para Andalucía, al igual que el anterior, se pueden descargar las ortofotografías realizadas por CMAOT, desde la web de descargas de la REDIAM, y consultar mediante su dirección WMS ${ }^{17}$.

Entre los años 1980 y 1999 hay, además, varios vuelos fotogramétricos, de los que no se dispone de más referencias, pero que se pueden descargar, georreferenciados, pero no ortorectificados, de la fototeca del Instituto de Estadística y Cartografía de Andalucía (IECA) ${ }^{18}$.

En el año 1997-98 se realizan los vuelos del SIG Oleícola, que fueron los primeros publicados en Internet, y se pueden descargar para Andalucía, las ortofotografias de la página de descargas de la REDIAM citada anteriormente y consultada mediante la dirección WMS asignada $^{19}$.

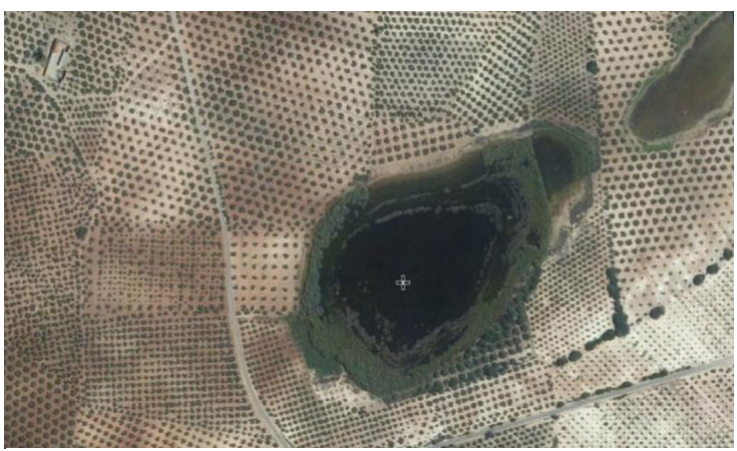

Figura 4. Laguna de los Jarales (TM Lucena). Ortofoto Digital de Andalucía Rigurosa Color 2010-2011.

Fuente: IECA

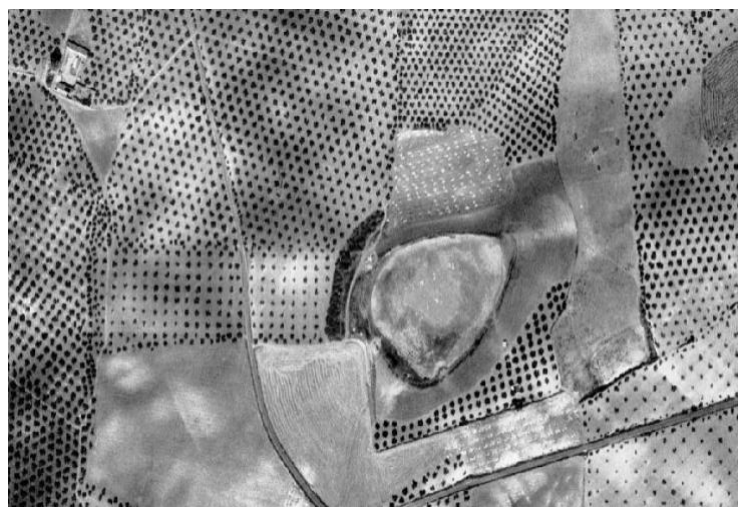

Figura 5. Laguna de los Jarales (TM Lucena). Ortofoto año 1984-85 (B/N).

Fuente: REDIAM

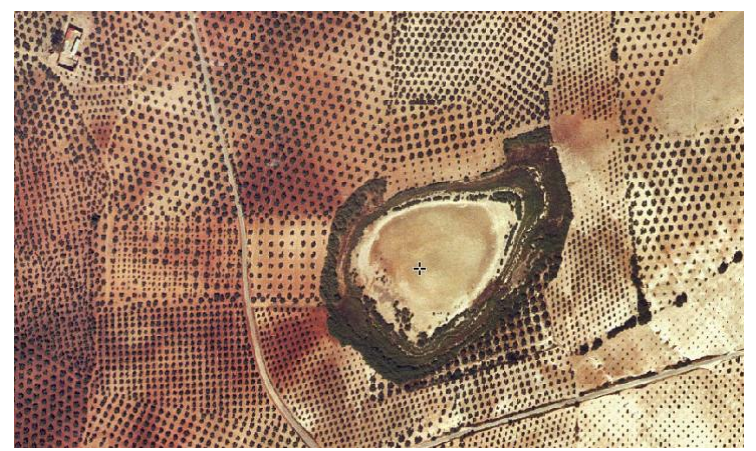

Figura 9. Laguna de los Jarales (TM Lucena). Ortofoto Digital de Andalucía Color 2004. Resolución 1m IECA. Fuente: IECA

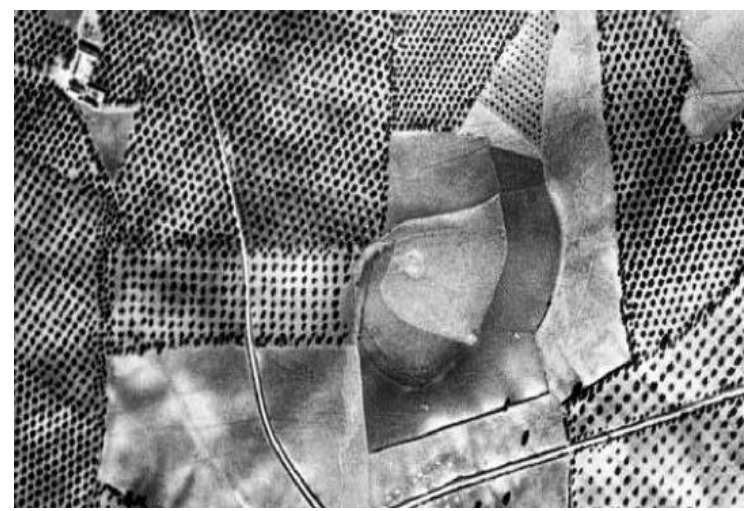

Figura 11. Laguna de los Jarales (TM Lucena). Ortofoto Vuelo Americano año 1956. Fuente: REDIAM

17 http://www.juntadeandalucia.es/medioambiente/mapwms/REDIAM Ortofoto PAN Andalucia 8485 [último acceso: $20 / 04 / 2017]$.

${ }^{18} \mathrm{http}: / /$ www.juntadeandalucia.es/institutodeestadisticaycartografia/fototeca/ [último acceso: 20/04/2017].

19 http://www.juntadeandalucia.es/medioambiente/mapwms/REDIAM_Ortofoto_PAN_Sig_Oleicola_1997_98? [último acceso: 20/04/2017]. 
Vega-Pozuelo, R., Torres-Márquez, M. y Naranjo-Ramírez, J. (2017): “Recursos cartográficos y geohistóricos para el inventario de humedales temporales y desecados mediterráneos”, GeoFocus (Artículos), no 19, p. 151-179. ISSN: 1578-5157 http://dx.doi.org/10.21138/GF.540

cial de Andalucía (LINE@) ${ }^{20}$ o desde la REDIAM ${ }^{21}$; y, para España, las correspondientes al PNOA, desde el año 2004 con una cadencia bianual, desde la web de descargas del $\mathrm{CNIG}^{22}$.

Los originales de los vuelos fotogramétricos del IGN están custodiados por la Fototeca del Centro Nacional de Información Geográfica (CNIG), organismo que se encarga también de la difusión de esa información. Disponen de vuelos fotogramétricos con fechas que abarcan desde los años 30 hasta la actualidad. Parte de los fotogramas están digitalizados para una mejor gestión y conservación, principalmente fotogramas alternos. Actualmente el IGN está interesado en disponer de las colecciones completas de todos los vuelos. Otro organismo que dispone de una extensa fototeca es el Ministerio de Medio Ambiente, que, entre otros fondos, custodia los originales del vuelo Interministerial.

Desde 2006 en adelante, los vuelos del PNOA (Plan Nacional de Ortofotografía Aérea) se realizan con cámara aérea digital.

Para consultar los vuelos fotogramétricos se puede acudir al visualizador de la Fototeca Digital $^{23}$, en la sede de la Fototeca en la Casa del Mapa de Madrid o mediante otros medios de contacto (telefónico y correos electrónico o convencional).

\section{8.- Inventarios de vías pecuarias}

Las vías pecuarias son los caminos que se utilizaban, desde el Medievo, para el tránsito del ganado. Tienen una regulación especial desde el siglo XIII, cuando Alfonso X crea el Honrado Concejo de la Mesta de los Pastores de Castilla, si bien, los cambios en los usos y aprovechamientos ganaderos han generado una drástica modificación de sus condiciones originales.

No se puede hablar de vías pecuarias sin comentar brevemente los actos administrativos por las que éstas se definen en la actualidad y con el fin de recuperar ese patrimonio viario de dominio público que, en multitud de ocasiones, se ha perdido o ha sido ocupado o usurpado por otros usos. Son fundamentalmente tres:

- La clasificación, es el acto por el que se declara la existencia de la vía pecuaria.

- El deslinde, es el acto por el que se definen los límites exactos de la vía pecuaria.

- El amojonamiento, es el acto mediante el que se identifican físicamente los límites establecidos en el deslinde.

\footnotetext{
${ }^{20} \mathrm{http} / / / \mathrm{www}$.juntadeandalucia.es/institutodeestadisticaycartografia/lineav2/web/ [último acceso: 20/04/2017].

21 http://ws041.juntadeandalucia.es/medioambiente/dlidar/index.action [último acceso: 20/04/2017].

22 http://centrodedescargas.cnig.es [último acceso: 20/04/2017].

${ }^{23}$ http://fototeca.cnig.es/ [último acceso: 20/04/2017].
} 


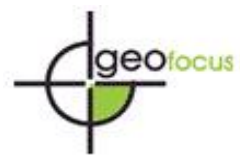

Vega-Pozuelo, R., Torres-Márquez, M. y Naranjo-Ramírez, J. (2017): “Recursos cartográficos y geohistóricos para el inventario de humedales temporales y desecados mediterráneos”, GeoFocus (Artículos), no 19, p. 151-179. ISSN: 1578-5157 http://dx.doi.org/10.21138/GF.540

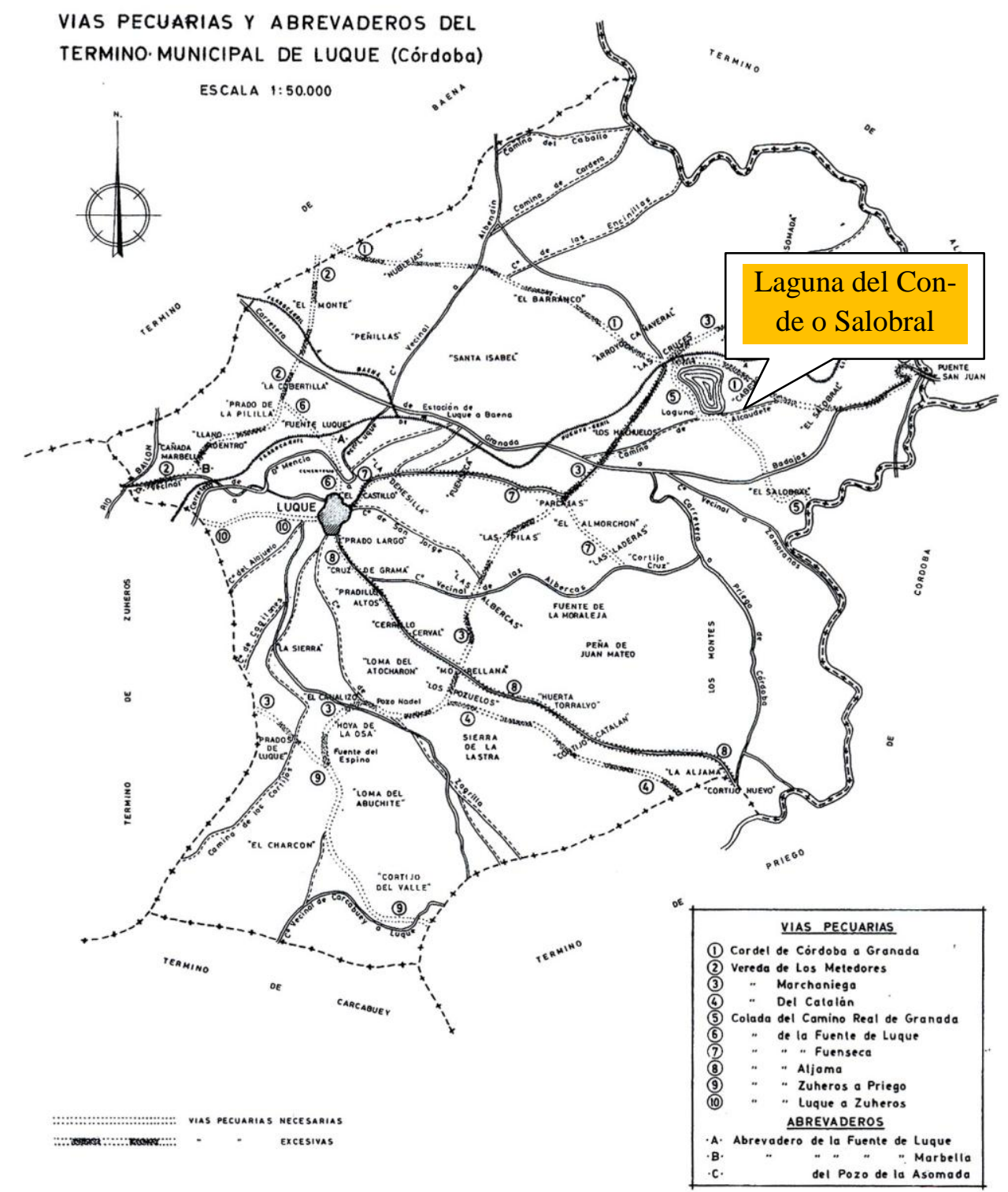

Figura 12. Croquis de las vías pecuarias y abrevaderos de Luque (Córdoba). Año 1957-58.

Fuente: Consejería de Medio Ambiente y Ordenación del Territorio (REDIAM). Junta de Andalucía.

Por fortuna, en Andalucía casi todos los términos municipales disponen de una clasificación de vías pecuarias, que, en la mayoría de los casos, se realizó en los años 50 y 60 del siglo $\mathrm{XX}$, aunque en algunos ejemplos hay antecedentes de principios del mismo siglo. No es así en otras comunidades autónomas, donde gran parte de los municipios no poseen clasificación.

El catálogo textual de vías pecuarias de Andalucía, procedente de los proyectos de clasificación, está disponible para su descarga en la página de la REDIAM, para algunas provincias. 
Vega-Pozuelo, R., Torres-Márquez, M. y Naranjo-Ramírez, J. (2017): “Recursos cartográficos y geohistóricos para el inventario de humedales temporales y desecados mediterráneos", GeoFocus (Artículos), no 19, p. 151-179. ISSN: 1578-5157 http://dx.doi.org/10.21138/GF.540

\section{Resultados}

A continuación, a modo de compilación y síntesis del análisis documental previo, se enumeran los pasos o ítems a seguir, en virtud de la cronología y calidad de las fuentes citadas, a modo de propuesta metodológica, en el uso de recursos cartográficos para el inventario de humedales temporales en el Medio Guadalquivir, expresión del protocolo de análisis que estamos siguiendo en nuestra investigación para el referido territorio:

1. ¿El terreno es público o privado?

2. Necesidad de consultar las vías pecuarias y otros caminos públicos que transcurren por la zona, y estudiar detalladamente su descripción literaria, sobre todo en lo referente a sus lugares asociados (descansaderos, abrevaderos, cruces, etc.) porque en ellos se ubican algunos de estos humedales.

3. Consultar si en el Ayuntamiento correspondiente existe inventario de bienes públicos y otras zonas de dominio público, y si cuenta con cartografía propia a este respecto.

4. Si no hay inventario de zonas de dominio público, comenzar la búsqueda de fuentes para investigar la presencia de humedales. Ordenarlas, en función de su accesibilidad por parte de los investigadores:

a. Plano de la $1^{\text {a }}$ edición del MTN. Si aparece algún humedal de pequeño tamaño es posible que siga existiendo en la actualidad. El nombre del humedal ofrece indicios, en caso de estar desecado en la actualidad. Contrastarlo si es posible con los distintos catastros. Si no aparece, buscar en otros planos antiguos o catastros, lo cual añade más dificultad al proceso.

b. Catastro moderno. Si no se localizan humedales puede ser señal de que han sido desecados (lo que no significa que no se puedan restaurar). Si aparece en este catastro y en los planos antiguos, es que se ha mantenido con el tiempo, y es probable que se pueda comprobar mediante visita de campo.

c. Catastro parcelario. Si aparece como límite de polígonos, el humedal debe ser público según la normativa del catastro.

d. Otros planos en cartotecas. En el caso del Medio Guadalquivir (Andalucía), en la Cartoteca Digital, y, sobre todo, si se encuentra el catastro por masas de cultivo.

e. Si se ha localizado un humedal en los planos antiguos, para delimitarlos, se pueden utilizar las ortofotos, principalmente las de 1956-57 y 1978-83.

5. Se requiere consultar si se pueden utilizar otro tipo de servidumbres (ríos, arroyos, costa, canales, etc.)

\section{5.- Conclusiones y discusión}

El presente trabajo reconoce y pone en valor que el inventario de los humedales de una determinada región, así como su clasificación tipológica, son pasos imprescindibles para el reconocimiento social de un patrimonio necesario de conservar.

La importancia, ya aceptada de forma generalizada, del uso de fuentes de información en el campo del inventario de humedales, la clasificación y la divulgación y puesta al servicio de los gestores, obliga a los investigadores a disponer de un exhaustivo y actualizado método de trabajo, en el que el uso de las fuentes es primordial. Se trata de una utilización en tiempo real, 
Vega-Pozuelo, R., Torres-Márquez, M. y Naranjo-Ramírez, J. (2017): “Recursos cartográficos y geohistóricos para el inventario de humedales temporales y desecados mediterráneos”, GeoFocus (Artículos), no 19, p. 151-179. ISSN: 1578-5157 http://dx.doi.org/10.21138/GF.540

en la que el documentalista ofrece las ventajas de las principales fuentes con las que han de elaborar sus propuestas.

Tal y como se ha expuesto en el presente trabajo, desde hace casi una década se viene diferenciando entre fuentes de información geográfica clásicas, -fundamentalmente libros y revistas, ya que seguimos alimentándonos de la cultura impresa- y fuentes de información geográfica electrónicas, "on-line" o fuentes actualizadas en tiempo real, es decir, los mismos conceptos, pero utilizando soportes multimedia, en los que el texto está acompañado de imágenes, sonido, gráficos, animación, vídeo, etc. En esta línea, por supuesto, ha de reconocerse el valor de las iniciativas digitalizadoras de diferentes organismos (institutos, bibliotecas, cartotecas, academias, etc.), que están digitalizando los fondos históricos que atesoran su archivos y colecciones documentales. Tales iniciativas suponen un ingente trabajo y una importante inversión económica, pero, al mismo tiempo, están complementando la información geográfica y cartográfica actual que se pone a disposición a través de las Infraestructuras de Datos Espaciales (IDE). Un complemento que, por otra parte, supone un importante ahorro de tiempo para la investigación y una facilidad de acceso a los documentos verdaderamente imponderable.

A lo largo del mismo, se expone una breve guía metodológica para el inventario de humedales. Debe ser tomada de forma orientativa, porque requiere ser completada con el uso de la teledetección (Uriós, 1997), haciendo uso principalmente de imágenes de media y alta resolución geométrica; como ejemplo podrían utilizarse los mosaicos imágenes de satélite corregidas y ortoimágenes disponibles en la REDIAM (visor comparador). Se disponen de imágenes desde 1975 a la actualidad, de fuentes documentales, bibliográficas o de la evidente necesidad de un importante trabajo de campo, lo cual es objeto de otras líneas de investigación. Por otro lado, el uso de imágenes de satélite con resolución temporal alta permite llevar a cabo una caracterización del comportamiento del humedal en lo que respecta al hidroperiodo y el régimen hidrológico, es decir, con el patrón de inundación y vaciado del mismo.

Finalmente, como es sabido, cualquier localización cartográfica de un humedal habrá que contrastarla siempre con la visita de campo y con la entrevista a agentes del territorio (propietarios, cronistas oficiales, técnicos de cultura o medio ambiente, agentes medioambientales, guardas de cotos de caza, etc.)

A lo largo de nuestro trabajo se han apuntado las posibles limitaciones, potencialidades y errores a los que puede inducir la consulta de las distintas fuentes documentales cartográficas, dificultades de acceso o consulta y previsibles potencialidades para sistematizar la realización de inventarios de humedales. No obstante, parece interesante enfatizar algunos aspectos significativos. En concreto, destacamos:

- La posibilidad de consulta en línea (mediante servicios WMS, WCS, etc.) abre campos de acción directa o instantánea, desde los que se pueda llegar a completar, entre otros muchos aspectos geoculturales o ambientales, el inventario de humedales temporales o desecados, ya que el desarrollo y la creciente difusión de las Infraestructuras de datos espaciales está suponiendo una verdadera revolución para los levantamientos de información geotemática.

- Los recursos cartográficos para el inventario de humedales temporales o desecados en el Medio Guadalquivir son, a la vista de lo analizado a lo largo del presente trabajo, muy amplios y de orígenes muy dispersos: legajos y mapas históricos, libros electrónicos, información catastral, fotointerpretación, etc., pero la tendencia es a utilizar redes que engloben todos estos soportes, como podría ser Internet, especialmente en lo referente a conexiones remotas a servidores cartográficos. 
Vega-Pozuelo, R., Torres-Márquez, M. y Naranjo-Ramírez, J. (2017): “Recursos cartográficos y geohistóricos para el inventario de humedales temporales y desecados mediterráneos”, GeoFocus (Artículos), no 19, p. 151-179. ISSN: 1578-5157 http://dx.doi.org/10.21138/GF.540

- El análisis realizado muestra la necesidad de llevar a cabo una labor de integración definitiva de todas las fuentes cartográficas existentes, por parte de bibliotecas electrónicas, museos, archivos interactivos y otros sistemas aplicados al inventario de humedales. Por ello la administración pública debería potenciar y difundir socialmente las virtudes de los sistemas coordinados de acceso a la información o Infraestructuras de datos Espaciales (IDEs).

- Por último, resulta necesario indicar que existen otra serie de fuentes "no escritas" que pueden ser complementarias a las descritas en el presente trabajo, pero que, al mismo tiempo, pueden resultar de gran utilidad. En concreto, nos referimos a las fuentes artísticas, objetos cotidianos, fotografía, cinematografía, fuentes orales (memoria popular, cronistas, etc.) y fuentes arqueológicas.

\section{Referencias bibliográficas}

Bermúdez, J. (2001): La aplicación de Sistemas de Información Geográfica a la arqueología. Madrid, Universidad Autónoma de Madrid.

Bermejo, D., Cáceres, F. Moreira, J. M. (Coords.) (2011): Medio siglo de cambios en la evolución de usos del suelo en Andalucía 1956-2007. Sevilla, Consejería de Medio Ambiente de la Junta de Andalucía.

Berné Valero, J. L., Femenia Ribera, C., y Aznar Bellver, J. (2004): Catastro y valoración catastral. Valencia, Universidad Polítécnica de Valencia.

BOE, A. E. (29/031900): Gazeta: colección histórica..

https://www.boe.es/datos/pdfs/BOE//1900/088/A01134-01135.pdf (consultado 08-02-2016).

Campillo Besses, X. (2009): “Apunte metodológico para la realización de inventarios municipales de caminos según el reglamento de bienes", Jornadas de estudio de los caminos públicos en Segovia. Segovia, Diputación de Segovia.

Casado, S., y Montes, C. (1995): Guía de los Lagos y Humedales de España. Madrid, J.M. Reyero.

Cirujano, S. (1988): "Los humedales de la provincia de Albacete. Una panorámica general", Al Basit: Revista de estudios albacetenses, 24, 77-95.

Dantín, J. (1940): “La aridez y el endorreísmo en España. El endorreísmo bético", Estudios Geográficos, 1, 1, 75-117.

DGOH. (1991): Estudio de las Zonas Húmedas Continentales de España. Inventario, tipificación, relación con el régimen hídrico general y medidas de protección. Madrid, INITEC. Dirección General de Obras Hidráulicas, Ministerio de Obras Públicas y Transportes.

Fernández Escorial, M. (2005): "Documentación catastral conservada en el Archivo Histórico Provincial de Málaga: las transferencias del Catastro a los Archivos Históricos Provinciales", CT/Catastro, 54, 85-104.

Fernández Nieto, A. (2005): "El plano catastrón del Catastro Topográfico Parcelario", CT/Catastro, 53, 172-181.

Finlayson, C. (1999): "Global wetland inventory - current status and future priorities". Marine and Freshwater Research, 50, 8, 717-727. 
Vega-Pozuelo, R., Torres-Márquez, M. y Naranjo-Ramírez, J. (2017): “Recursos cartográficos y geohistóricos para el inventario de humedales temporales y desecados mediterráneos”, GeoFocus (Artículos), no 19, p. 151-179. ISSN: 1578-5157 http://dx.doi.org/10.21138/GF.540

González Bernáldez, F. (1987): “Las zonas encharcables españolas: el marco conceptual”. En F. y. Real Academia de Ciencias Exactas, Bases científicas para la protección de los humedales en España, 9-30. Madrid, Real Academia de Ciencias Exactas, Físicas y Naturales.

González Bernáldez, F. (1988): "Typology of wetlands and evaluation of the resources they represent", International Symposium on Hydrology Wetlands in Semiarid and Arid Regions. Sevilla, 7-36.

González Bernáldez, F. (1992): "Características esenciales del Paisaje Mediterráneo. La frutalización del Paisaje Mediterráneo" en Chaves González, M.: Paisaje Mediterráneo. Milán, Electa, 136-141.

Guerrero Ruiz, F., Ortega González, F., y Parra, G. (2003): "Los humedales del Alto Guadalquivir: inventario, tipologías y estado de conservación. Ecología, manejo y conservación de los humedales" en Paracuellos, M: Aula de Ecología. Almería, M. Paracuellos, 113-123.

Junta de Andalucía (s.f): Inventario de Humedales de Andalucía (IHA). Sevilla, Consejería de Medio Ambiente y Ordenación del Territorio de la Junta de Andalucía.

http://www.juntadeandalucia.es/medioambiente/site/portalweb/menuitem.7e1cf46ddf59bb227a9 ebe205510e1ca/?vgnextoid=cd65b44325234010VgnVCM1000000624e50aRCRD\&vgnextchan nel=2b439d7f4c335310VgnVCM1000001325e50aRCRD\#inicio (consultado 20/04/2017).

Junta de Andalucía (2002): Plan Andaluz de Humedales (PAH). Sevilla, Consejería de Medio Ambiente y Ordenación del Territorio de la Junta de Andalucía.

Junta de Andalucía (2005): Caracterización de los Humedales en Andalucía. Sevilla, Consejería de Medio Ambiente.

Martínez Laceras, J. L. (2000): "El cálculo de las bases imponibles en la antigua Contribución Rústica y en el actual Impuesto de Bienes Inmuebles de Naturaleza Rústica”, CT/Catastro, 41, 7-21.

Meynier, A. (1968): Los paisajes agrarios. Bilbao, Moretón.

Montes, C., y Martino, P. (1987): "Las lagunas salinas españolas" en Real Academia de Ciencias Exactas: Bases Científicas para la protección de los humedales en España. Madrid, Real Academia de Ciencias Exactas, Físicas y Naturales, 95-145.

Moya García, E., Cuesta Aguilar, Ma . J. y Sánchez Martínez, J. D. (2016): "El olivar jiennense en los levantamientos topográficos del Instituto Geográfico y Estadístico (1874-1883)", Documents d'anàlisi geogràfica, 62, 2, 373-402. DOI: http://dx.doi.org/10.5565/rev/dag.313

Muro Morales, J. I; Urteaga González, L. y Nadal Piqué, F. (1996): Geografía, estadística y catastro en España: 1856-1870. Barcelona, Ediciones del Serbal.

Naranjo-Ramírez, J. (2013): "Las Campiñas del Guadalquivir: claves para una interpretación geográfica”, Revista de Estudios Regionales, 96, 99-134.

Naranjo-Ramírez, J. y Vega-Pozuelo, R. (2015). "Inventario abierto, cartografía y estudio del paisaje de los humedales temporales mediterráneos: resultados preliminares" en Junta de Andalucía: Congreso Nacional de Conservación y Restauración de Humedales, Jerez de la Frontera, Consejería de Medio Ambiente y Ordenación del Territorio, 107.

Pardo, L. (1948): Catálogo de Lagos de España. Biología de las Aguas Continentales. Madrid, Instituto Forestal de Investigaciones y Experiencias.

Pita, M. F. (2003): "Geografía de Andalucía” en López Ontiveros, A. (Coor.): Geografía de Andalucía. Barcelona, Ariel, 137-174. 
Vega-Pozuelo, R., Torres-Márquez, M. y Naranjo-Ramírez, J. (2017): “Recursos cartográficos y geohistóricos para el inventario de humedales temporales y desecados mediterráneos”, GeoFocus (Artículos), no 19, p. 151-179. ISSN: 1578-5157 http://dx.doi.org/10.21138/GF.540

Ruiz Morales, M. (2005): "Los primeros trabajos del Instituto Geográfico", Mapping Interactivo, 103, 6-17.

Sastre Domingo, J., y Yuste Galán, A. (2004): "La memoria en los archivos del Instituto Geográfico Nacional (IGN)", TopCart, 2004, 63-64.

Torres-Márquez, M. (2012): "El paisaje rural según el parcelario catastral y sus Memorias de la riqueza rústica de 1899. El término municipal de Córdoba (España)", Scripta Nova. Revista Electrónica de Geografía y Ciencias Sociales, 16, 409.

Torres-Márquez, M. (2016): “Córdoba en las «minutas cartográficas» del Instituto Geográfico Nacional (1871-1900) y su hábitat rural como herramienta cartográfica”, Investigaciones Geográficas, 65, 75-96.

Uriós, G. (1997): “Teledetección aplicada al estudio de humedales”, Boletín SEHUMED, 4, 1-2.

Urteaga, L. y Nadal, F. (2001): Las series del mapa topográfico de España a escala 1:50.000. Madrid, Instituto Geográfico Nacional.

Urteaga, L. (2008): "Dos décadas de investigación sobre la historia de la cartografía catastral en España (1988-2008)”, CT/Catastro, 63, 7-30.

Vales, J.J, Carpintero, I., Granado, L., Méndez, E., Motoya, G., Pino, I., y otros. (2010): "Producción de ortofotos históricas para la generación de bases de datos temáticas. Cartografía de usos y coberturas del suelo. REDIAM" en Ojeda, J., Pita, M. y Vallejo, I, (Coor.): Tecnologías de la Información Geográfica: la Información Geográfica al servicio de los ciudadanos. Sevilla, Universidad de Sevilla., 370-384.

Vázquez Maure, F. (1982): "La toponimia en el Mapa Topográfico Nacional", Boletín de la Real Sociedad Geográfica, 118, 99-104.

Vega-Pozuelo, R. (2002): Inventario abierto, cartografía y caracterización de los humedales de la cuenca media del Guadalquivir; primeros pasos para su conservación. Córdoba, Universidad de Córdoba. Inédito.

Vélez, F. (1984): “Inventario de las zonas húmedas andaluzas" en D. G. Urbanismo: Las Zonas Húmedas en Andalucía. Madrid, Servicio de Publicaciones del Ministerio de Obras Públicas y Urbanismo, 13-22.

Villalvilla, H. (2012): "Las servidumbres y los caminos públicos”, Ecologistas, 73, 45-47.

Williams, W. (1999): "Conservation of wetlands in drylands: a key global issue", Aquatic Conservation: Marine and Freshwater Ecosystems, 9, 517-522. 
Vega-Pozuelo, R., Torres-Márquez, M. y Naranjo-Ramírez, J. (2017): “Recursos cartográficos y geohistóricos para el inventario de humedales temporales y desecados mediterráneos", GeoFocus (Artículos), no 19, p. 151-179. ISSN: 1578-5157 http://dx.doi.org/10.21138/GF.540

\section{Annexo}

\begin{tabular}{|c|c|c|c|c|}
\hline \multicolumn{5}{|c|}{ Repositorios de fotografía aérea histórica y actual } \\
\hline Fecha & Nombre & $\begin{array}{l}\text { Escala } \\
\text { aprox. }\end{array}$ & Descarga & $\begin{array}{c}\text { WMS } \\
\text { [último acceso: } \\
\text { 20/04/2017] }\end{array}$ \\
\hline $1945 / 46$ & Vuelo Americano Serie A (B/N) & $1: 43.000$ & $\begin{array}{l}\text { Fototeca CNIG (geo- } \\
\text { rref aprox.) }\end{array}$ & $\begin{array}{l}\text { http://fototeca.cnig.es/w } \\
\text { ms/fototeca.dll? }\end{array}$ \\
\hline $1956 / 57$ & Vuelo Americano Serie B (B/N) & $1: 33.000$ & $\begin{array}{l}\text { Esp: Fototeca CNIG } \\
\text { (georref aprox.) } \\
\text { And: LINEA y } \\
\text { Ortofotos REDIAM }\end{array}$ & $\begin{array}{l}\text { http://fototeca.cnig.es/w } \\
\text { ms/fototeca.dll? } \\
\text { (aprox.) } \\
\text { http://www.juntadeanda } \\
\text { lucia.es/medioambiente/ } \\
\text { mapwms/REDIAM Ort } \\
\text { ofoto_Andalucia_1956 }\end{array}$ \\
\hline 1973 & Vuelo CEFTA (B/N) & $1: 25.000$ & $\begin{array}{l}\text { Provincia de Córdoba: } \\
\text { Visor Diputación }\end{array}$ & \\
\hline 1973/86 & Interministerial $(\mathrm{B} / \mathrm{N})$ & 1:18.000 & $\begin{array}{l}\text { Esp: Fototeca CNIG } \\
\text { (georref aprox.) } \\
\text { And: Ortofotos } \\
\text { REDIAM }\end{array}$ & $\begin{array}{l}\underline{\text { http://fototeca.cnig.es/w }} \\
\underline{\text { ms/fototeca.dll? }} \\
\text { (aprox.) } \\
\text { http://www.juntadeanda } \\
\underline{\text { lucia.es/medioambiente/ }} \\
\text { mapwms/REDIAM_Ort } \\
\text { ofoto BN 1977 83 }\end{array}$ \\
\hline $1980 / 82$ & Vuelo analógico $(\mathrm{B} / \mathrm{N})$ & $1: 25.000$ & And: Fototeca IECA & \\
\hline $1984 / 85$ & Vuelo analógico (B/N) & $1: 40.000$ & And: Fototeca IECA & \\
\hline $1980 / 86$ & $\operatorname{IGC}(\mathrm{B} / \mathrm{N})$ & $1: 33.000$ & $\begin{array}{l}\text { Esp: Fototeca CNIG } \\
\text { (georref aprox.) } \\
\text { And: Ortofotos RE- } \\
\text { DIAM }\end{array}$ & $\begin{array}{l}\underline{\text { http://fototeca.cnig.es/w }} \\
\text { ms/fototeca.dll? } \\
\text { (aprox.) } \\
\text { http://www.juntadeanda } \\
\underline{\text { lu- }} \\
\underline{\text { cia.es/medioambiente/m }} \\
\text { apwms/REDIAM Ortof } \\
\underline{\text { oto_PAN_Andalucia_8 }} \\
\underline{4 \_85}\end{array}$ \\
\hline 1991/96 & Vuelo analógico (B/N) & $1: 20.000$ & And: Fototeca IECA & \\
\hline $1995 / 96$ & Vuelo analógico (B/N) & 1:60.000 & And: Fototeca IECA & \\
\hline $1997 / 98$ & SIG Oleícola $(\mathrm{B} / \mathrm{N})$ & $1: 30.000$ & & $\begin{array}{l}\text { http://www.juntadeanda } \\
\text { lu- } \\
\text { cia.es/medioambiente/m } \\
\text { apwms/REDIAM_Ortof } \\
\text { oto PAN Sig Oleicola } \\
\text { 1997_98? }\end{array}$ \\
\hline 1998/99 & Ortofoto Andalucía (color) & 1:60.000 & & $\begin{array}{l}\text { http://www.ideandaluci } \\
\text { a.es/wms/ortofoto1998 }\end{array}$ \\
\hline 2001/02 & Ortofoto Andalucía (B/N) & $1: 20.000$ & & $\begin{array}{l}\text { http://www.ideandaluci } \\
\text { a.es/wms/ortofoto2001 }\end{array}$ \\
\hline 2004 & Ortofoto Andalucía (color) & $1: 60.000$ & & $\begin{array}{l}\text { http://www.ideandaluci } \\
\text { a.es/wms/ortofoto2004 }\end{array}$ \\
\hline $2004 / 05$ & PNOA (color) & $1: 20.000$ & & http://www.ign.es/wms/ \\
\hline
\end{tabular}


Vega-Pozuelo, R., Torres-Márquez, M. y Naranjo-Ramírez, J. (2017): “Recursos cartográficos y geohistóricos para el inventario de humedales temporales y desecados mediterráneos”, GeoFocus (Artículos), no 19, p. 151-179. ISSN: 1578-5157 http://dx.doi.org/10.21138/GF.540

\begin{tabular}{|c|c|c|c|}
\hline & & & pnoa-historico \\
\hline $2006 / 07$ & PNOA (color) & $1: 20.000$ & $\begin{array}{l}\text { http://www.ign.es/wms/ } \\
\text { pnoa-historico }\end{array}$ \\
\hline 2007 & Ortofoto Andalucía (color) & $1: 60.000$ & $\begin{array}{l}\text { http://www.ideandaluci } \\
\text { a.es/wms/ortofoto2007 }\end{array}$ \\
\hline 2008/09 & PNOA (color) & $1: 20.000$ & $\begin{array}{l}\text { http://www.ideandaluci } \\
\text { a.es/wms/ortofoto2009 }\end{array}$ \\
\hline 2010/11 & PNOA (color) & $1: 20.000$ & $\begin{array}{l}\text { http://www.ideandaluci } \\
\text { a.es/wms/ortofoto2010 }\end{array}$ \\
\hline $2012 / 13$ & PNOA (color) & $1: 60.000$ & $\begin{array}{l}\text { http://www.ign.es/wms- } \\
\text { inspire/pnoa-ma? }\end{array}$ \\
\hline
\end{tabular}

\section{Visores y aplicaciones cartográficas}

\section{Genéricos:}

- Geoportal del Ministerio de Agricultura y Pesca, Alimentación y Medio Ambiente, http://sig.magrama.es/geoportal/ [último acceso: 21/04/2017].

Sólo incorpora por defecto ciertas capas del Ministerio, pero permite añadir nuevas.

- Visor Line@ (Consejería de Economía, Innovación, Ciencia y Empleo de la Junta de Andalucía), http://www.juntadeandalucia.es/institutodeestadisticaycartografia/lineav2/web/ [último acceso: 21/04/2017].

- IDEAVisor (Instituto de Estadística y Cartografía de Andalucía): http://www.ideandalucia.es/portal/web/ideandalucia/datos-y-servicios/ideavisor [último acceso: 21/04/2017].

- Visor Iberpix (Instituto Geográfico Nacional): http://www.ign.es/iberpix2/visor/ [último acceso: 21/04/2017]. Organizado por capas, además de incluir la representación del relieve mediante Modelo Digital del Terreno (MDT) y los usos del suelo de toda España (SIOSE).

- Visor genérico OGC Rediam (Junta de Andalucía): permite la consulta de información espacial sobre diversos marcos de referencia (Google Map, Bing, OpenStreetMap o Junta de Andalucía), con las capas precargadas de Espacios Naturales Protegidos, Montes Públicos, Subsistema de Humedales, etc.

- Comparador WMS Ortofotos de Andalucía (REDIAM): permite comparar ortofotos de diferentes fechas y valorar los cambios que se han producido en un territorio.

\section{Temáticos:}

- Visor de Humedales (REDIAM):

http://laboratoriorediam.cica.es/VisorHumedales/?lr=lang_es [último acceso: 21/04/2017], con las capas más útiles para la localización de humedales andaluces (humedales Ramsar, Inventario de Humedales de Andalucía, Mapas de Cuencas vertientes, etc.)

- Visor SigPac (Ministerio de Agricultura): http://sigpac.mapa.es/fega/visor/ [último acceso: 21/04/2017]. Es un visor nacional con fotografía aérea y planimetría a escala 1:25.000 de la totalidad del territorio nacional. Su principal ventaja es que ofrece la posibilidad de vista de los parcelarios.

- Visor del Instituto Geológico y Minero de España (IGME): 
Vega-Pozuelo, R., Torres-Márquez, M. y Naranjo-Ramírez, J. (2017): “Recursos cartográficos y geohistóricos para el inventario de humedales temporales y desecados mediterráneos”, GeoFocus (Artículos), no 19, p. 151-179. ISSN: 1578-5157 http://dx.doi.org/10.21138/GF.540

http://info.igme.es/visorweb/ [último acceso: 21/04/2017]. Permite navegar y visualizar la cartografía geológica a distintas escalas en toda la extensión territorial española, así como superponer información espacial de Bases de Datos.

- Visor de índices de vegetación de Andalucía (REDIAM): http://laboratoriorediam.cica.es/VisorIndicesVegetacion/ [último acceso: 21/04/2017].

- Sistema de Información Urbana (SIU):

http://www.fomento.gob.es/MFOM/LANG_CASTELLANO/ ESPECIALES/SIU/SIU 2/VISOR/ [último acceso: 21/04/2017]. Sistema de información que ofrece información urbanística de un gran número de municipios y datos sobre ocupación de suelo obtenidos del proyecto CORINE Land Cover 2006 y del Sistema de Información de la Ocupación de Suelo en España (SIOSE).

- Visor privado Goolzoom: http://www.goolzoom.com [último acceso: 21/04/2017]. Herramienta organizada por capas, que permite visualizar las fincas catastrales, analizar datos del registro sobre capas de Plan Nacional de Ortofotografía Aérea (PNOA), del visor de fincas rurales catastrales (SIGPAC), del visor de cartografía urbana Cartociudad, etc. 
Vega-Pozuelo, R., Torres-Márquez, M. y Naranjo-Ramírez, J. (2017): “Recursos cartográficos y geohistóricos para el inventario de humedales temporales y desecados mediterráneos”, GeoFocus (Artículos), no 19, p. 151-179. ISSN: 1578-5157 http://dx.doi.org/10.21138/GF.540

Otros servicios WMS de interés

Catálogos de servicios

- Nacional: http://www.idee.es/web/guest/directorio-de-servicios [último acceso: 20/04/2017].

- Andalucía: http://www.ideandalucia.es/index.php/es/catalogo-de-servicios [último acceso: 20/04/2017].

- Del Ministerio de Agricultura, Alimentación y Medio Ambiente: http://www.magrama.gob.es/es/biodiversidad/servicios/banco-datos-naturaleza/servidorcartografico-wms-/ [último acceso: 20/04/2017].

Cartografía básica nacional

- Mapa Topográfico Nacional ráster 1:25.000 http://www.idee.es/wms/MTN-Raster/MTNRaster? [último acceso: 20/04/2017].

- Mapa Topográfico vectorial (menos detallado) http://www.ign.es/wms-inspire/ign-base? [último acceso: 20/04/2017].

- Modelo Digital del Terreno (con elevaciones) http://www.idee.es/wms/IDEE-RelieveUTM30N/IDEE-Relieve-UTM30N? [último acceso: 20/04/2017].

- Catastro http://ovc.catastro.meh.es/Cartografia/WMS/ServidorWMS.aspx? [último acceso: 20/04/2017].

- $\quad$ Fototeca del IGN

Cartografía básica de Andalucía

- Cartografía vectorial 1:100.000 http://www.ideandalucia.es/wms/dea100 (conjunto básico) [último acceso: 20/04/2017].

http://www.ideandalucia.es/wms/mta100v_2005? (completo) [último acceso: 20/04/2017].

- Cartografía vectorial 1:10.000 http://www.ideandalucia.es/wms/mta10v 2007? [último acceso: 20/04/2017].

- Cartografía ráster 1:10.000 http://www.ideandalucia.es/wms/mta10r_2001 [último acceso: 20/04/2017].

Cartografía temática nacional

- Dominio público marítimo-terrestre http://wms.magrama.es/sig/Costas/DPMT/wms.aspx [último acceso: 15/02/2016].

- Dominio público hidráulico deslindado http://wms.magrama.es/sig/agua/DPHDeslindado/wms.aspx [último acceso: 15/02/2016].

- Dominio público hidráulico estimado http://wms.magrama.es/sig/agua/DPHEstimado/wms.aspx [último acceso: 15/02/2016].

- Inventario de tramos con estudio http://wms.magrama.es/sig/agua/ZI_TramosPNI/wms.aspx [último acceso: 15/02/2016].

- Primera edición del Mapa Topográfico Nacional http://www.idee.es/wms/IGN1EdicionMTN50/IGN-1EdicionMTN50 [último acceso: 15/02/2016].

- Montes de Utilidad Pública http://wms.magrama.es/sig/Biodiversidad/PropiedadMontes UP/wms.aspx? [último acceso: $15 / 02 / 2016]$.

- $\quad$ Titularidad de los montes http://wms.magrama.es/sig/Biodiversidad/PropiedadMontes/wms.aspx? [último acceso: 15/02/2016].

- Vías pecuarias http://wms.magrama.es/sig/Biodiversidad/ViasPecuarias/wms.aspx [último acceso: $15 / 02 / 2016]$.

Cartografía temática de Andalucía 
Vega-Pozuelo, R., Torres-Márquez, M. y Naranjo-Ramírez, J. (2017): “Recursos cartográficos y geohistóricos para el inventario de humedales temporales y desecados mediterráneos”, GeoFocus (Artículos), no 19, p. 151-179. ISSN: 1578-5157 http://dx.doi.org/10.21138/GF.540

- Mapas-guía de parques naturales http://www.ideandalucia.es/wms/espacios_naturales? [último acceso: 16/02/2016].

- Equipamientos de uso público (incluye senderos) de la Red de Espacios Naturales http://www.juntadeandalucia.es/medioambiente/mapwms/REDIAM_Equipamientos_Uso_ Publico_Andalucia? [último acceso: 16/02/2016].

- Inventario de árboles y arboledas singulares http://www.juntadeandalucia.es/medioambiente/mapwms/REDIAM arb abda singulares? [último acceso: 16/02/2016].

- Manantiales y fuentes de Andalucía (procedente del proyecto Conoce tus Fuentes) http://www.juntadeandalucia.es/medioambiente/mapwms/REDIAM_Manantiales_y_Fuent es? [último acceso: 16/02/2016].

- Inventario de bienes de la CMA http://www.juntadeandalucia.es/medioambiente/mapwms/REDIAM_Inventario_bienes_C MA? [último acceso: 16/02/2016].

- Montes públicos de Andalucía http://www.juntadeandalucia.es/medioambiente/mapwms/REDIAM_Montes_Publicos_An dalucia? [último acceso: 16/02/2016].

- Inventario de vías pecuarias http://www.juntadeandalucia.es/medioambiente/mapwms/REDIAM_Inventario_VVPP? [último acceso: 16/02/2016].

- $\quad$ Red Natura 2000 http://www.juntadeandalucia.es/medioambiente/mapwms/REDIAM_Red_Natura_2000? [último acceso: 16/02/2016].

- Límites de la Red de Espacios Protegidos http://www.juntadeandalucia.es/medioambiente/mapwms/REDIAM RENPA? [último acceso: $16 / 02 / 2016]$.

- Zonificación de los PORN vigentes http://www.juntadeandalucia.es/medioambiente/mapwms/REDIAMzonificacion_PORN_vi gentes? [último acceso: 16/02/2016].

- Inventario de georrecursos http://www.juntadeandalucia.es/medioambiente/mapwms/REDIAM_Georrecursos_Andalu cia 2011? [último acceso: 16/02/2016].

- Mapa del Estado Mayor Alemán, años 1940-1944 http://www.ideandalucia.es/wms/mta50r aleman 1944? [último acceso: 16/02/2016]. 
